\title{
Illusory Depth Based on Interactions Between Fluorescent and Conventional Colours: A Case Study on Frank Stella's Irregular Polygons Paintings
}

\author{
Stefanie De Winter ${ }^{1, *}$, Pieter Moors ${ }^{2}$, Hilde Van Gelder ${ }^{1}$ and Johan Wagemans ${ }^{2}$ \\ ${ }^{1}$ Art History Research Unit and Lieven Gevaert Centre, University of Leuven (KU Leuven), \\ Blijde-Inkomststraat 21 - bus 3313, 3000 Leuven, Belgium \\ ${ }^{2}$ Laboratory of Experimental Psychology, University of Leuven (KU Leuven), Tiensestraat \\ 102, 3000 Leuven, Belgium
}

Received 22 January 2018; accepted 3 September 2018

\begin{abstract}
Although Frank Stella intended to create flat, illusion-less Irregular Polygons paintings, it is not uncommon to experience the illusion of colour depth, based on the interaction between their fluorescent and conventional colours. Some critics praised these artworks' flatness, while others described odd depth experiences that they categorised as a new kind of illusion. In order to provide a correct reading of these works and to reassess their art historical significance, a scientific case study regarding this colour-depth effect imposes itself. This article discusses an experiment in which we determined whether twenty artists, twenty art historians and twenty laypeople experienced fluorescent colours as protruding, receding or flat in combination with conventional colours. We additionally looked at whether they still perceived colour depth when all fluorescent colours were replaced with their conventional variants. All participants observed fifteen designs, which they had to rate according to the perceived depth of each coloured region with a number between -3 (strongly receding) and +3 (strongly protruding). The results revealed that most participants experience fluorescent regions as strongly protruding, unlike all conventional colours, which were rated as much less protruding. When a fluorescent colour was swapped with a conventional variant, all participants experienced significantly less depth. The differences between the subject groups were statistically negligible when looking at the mean depth ratings for both colour types. However, we discovered that artists experienced more contrast effects, as they gave different ratings to different panels (of identical colour and shape) in the same design, depending on their position.
\end{abstract}

\section{Keywords}

Illusory colour depth, perception of paintings, fluorescent colours, Frank Stella, Irregular Polygons series

\footnotetext{
*To whom correspondence should be addressed. E-mail: stefanie.dewinter@kuleuven.be
} 


\section{Introduction}

The starting point of the experiment described here was a striking discrepancy between the first author's experience in conserving paintings of Frank Stella (1936) and her art historical research. Specifically, while studying the impact of fluorescent colours in Stella's paintings of the 60s, she was surprised that none of the visible effects that appear when observing these artworks were discussed in art historical literature. This gap turned out to be partly caused by not taking into account these impressions as relevant information when observing reproductions, simply because it is not possible to digitalize or reproduce artworks that contain fluorescence. The unusual effects of fluorescent colours had grabbed the first author's attention while conserving paintings of Frank Stella. Working on the actual paintings provided her with the opportunity to become fully aware of their material characteristics and their specifically fluorescence-related visual effects.

Before continuing, a general note on methodology is in order. Analysis and theory in art history take the individual phenomenology of a particular art historian as their starting point. The art historian will typically make claims about specific (visual) aspects of a particular work. To validate her claims, the art historian cannot appeal to anything further than to her own authority as an expert (connoisseur) (Van Gelder, 2003). If one disagrees, one basically has to contradict the original claim on the basis of subjective phenomenology. The argumentation that underlies the overall appreciation of the work therefore ultimately rests on a set of 'visual primitives' that in themselves cannot be further argued for. This is partly unavoidable due to the complexity of the (visual) material that is being assessed, but it has the unfortunate consequence that aesthetic appreciation is ultimately ungrounded beyond first-person phenomenology. In some cases, mainly in the consideration of abstract art, the visual phenomena that are being described by the art historian can be singled out to such an extent (mainly due to their relative simplicity), that they can be studied with methods from another discipline, namely, perceptual psychology. In these art works, a specific claim about a particular visual phenomenon gets 'temporarily exported' away from art history, into psychology. There, it becomes the subject of a controlled experiment, which has the goal to either refute the claim or to give it objective validity. The outcome of the experiment then gets reimported into the art historical practice, where in the case of invalidation, it leads to a revision of the original argument.

This article presents a case study that fits into this approach, specifically centred on the claim that illusory depth is experienced when looking at Frank Stella's Irregular Polygons paintings (Fig. 1 below). To turn it into a controlled experiment, however, we only focus on the role of colour in this depth effect. It is possible that this effect is also (partly) caused by other factors such as 


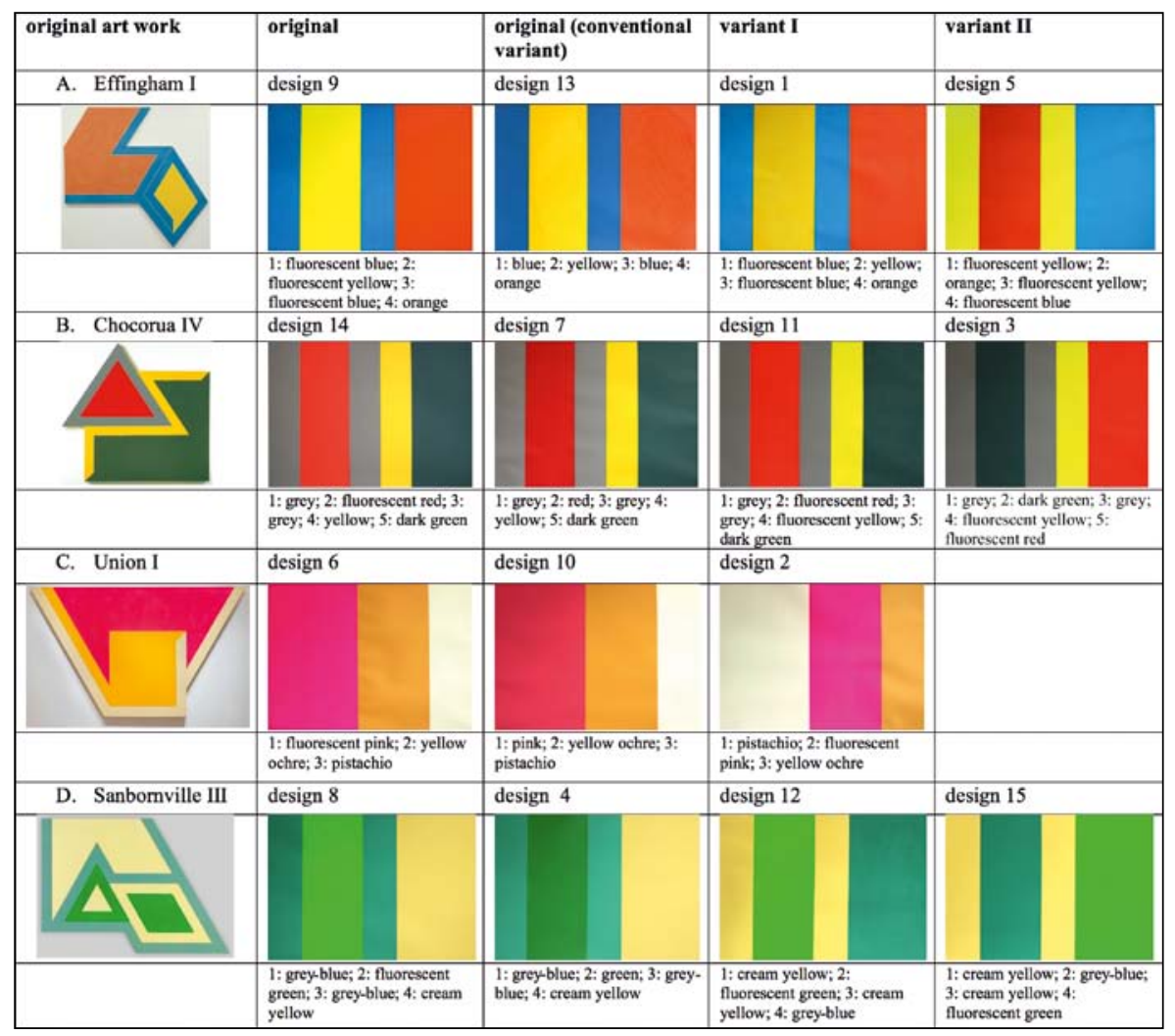

Figure 1. Original paintings and the designs based upon them. Stimulus designs based on Frank Stella (C) Stefanie De Winter), Irregular Polygons series (1965-66) (Note 6). (A) Effingham I (1966), fluorescent alkyd and epoxy paints on canvas, $325.12 \times 335.28 \times 10.16$ cm, Van Abbe museum, Eindhoven (@ SABAM Belgium 2018); (B) Chocorua IV (1966), fluorescent alkyd and epoxy paints on canvas, $304.8 \times 325.12 \times 10.16 \mathrm{~cm}$, Hood Museum of Art, Dartmouth College, Hanover, NH, USA (@ SABAM Belgium 2018); (C) Union I, fluorescent alkyd and epoxy paints on canvas, $261.62 \times 441.96 \times 10.16 \mathrm{~cm}$, Detroit Institute of Arts, MI, USA (@ SABAM Belgium 2018); (D) Sanbornville III (1966), fluorescent alkyd and epoxy paints on canvas, $264.16 \times 370.84 \times 10.16 \mathrm{~cm}$, Whitney Museum of American Art, New York, NY, USA (@ SABAM Belgium 2018).

RGB value of each conventional colour used in the designs: (A) yellow: 2542220 , blue: 0115 204, orange: 255138 92; (B) yellow: 254222 0, red: 224 35 87, grey: 179 182 189, dark green: 64124 125; (C) pink: 255122 186, yellow ochre: 250213115 , pistachio: 235255 247; (D) grey-blue: 73193 170, green: 25158 66, cream yellow: 237224142.

form and surface materiality characteristics, like gloss vs. matt, blurred edges, texture of the canvas, and the number of paint layers. We suspected that it is primarily caused by colour and therefore we isolated the colour combinations of four different paintings of this series: Effingham I, Chocorua IV, Union I 
and Sanbornville III (1965-1966). The exact steps of the method used will be outlined in Section 2.

First, a brief art historical overview will be given in order to situate the effects studied in this paper in their art historical context. To understand the differences between conventional and fluorescent colours, the introduction will also assess their chemical and physical differences, followed by a preliminary phenomenological description of the effects that are produced when both types of colour are combined. The transition from phenomenological observations to a controlled experiment is addressed in the second part, which contains a description of the artworks, the development of the designs and the setup. The participants who took part in this case-study can be divided in three groups: artists, art historians and laypeople; the reasons behind this choice have to do with the level of colour-depth training of each group and will be further explained in this section as well. The last part will focus on the results, first by providing a general analysis, followed by more detailed results of each separate design-group.

\subsection{Art Historical Background: Frank Stella's Irregular Polygons Series}

The experience of illusory colour depth through the interaction between fluorescent and conventional colours was first visible in New York paintings from the second half of the 1960s. Frank Stella was among the first artists who executed a series of paintings with a combination of conventional and fluorescent colours. After years of painting striped canvasses, Stella traded these patterns for compositions of simple, large coloured geometric shapes. The creation of the Irregular Polygons series was a next step in Stella's attempt to eliminate any form of illusion within the pictorial surface and thereby turning the painting into an object, a line of thought which he developed through his previous Black Paintings, Aluminum Paintings, etc.

For the Irregular Polygons series (1965-66) (Note 1) he developed eleven shaped canvasses of which each composition was executed four times in four different combinations of colour. When the first author asked Stella in an interview about his colour choice, he said: "To me, colour is simply colour" (De Winter, 2014, p. 1). He seemed to reduce his personal taste and intuitions as a painter in order to fully serve the needs of each single design: "Fluorescent colours seemed a good idea because my designs were, during that time, not that complex (De Winter, 2014, p. 1)". For this series, Stella said he arranged his colour compositions in the same 'superficially systematic' way as he combined the geometric shapes on his canvasses (Toledo Museum of Art, 2011).

From the eleven compositions, eight consist of two different coloured forms, two have three, and one has four different coloured shapes. In order to prevent 
the paintings from being hard-edged, he left a small area of canvas between each shape border unpainted. He used cheap artist tape that caused the paint to bleed, resulting in blurry edges. All shapes are held together by coloured bands (the width of the bands is $20.32 \mathrm{~cm}$ ) (Kennedy, 2010). Stella used a combination of fluorescent Day-Glo alkyd paint and conventional enamel paints, which caused an unintended and previously unseen kind of spatiality: "The effect generated by the coloured shapes flip-flopped between flatness and illusion" (Kennedy, 2010, p. 11). Although Stella initially wanted the paintings to be seen as flat and frontal, he later admitted that they appeared as what he called "planar ambiguities" (Rubin, 1970, p. 124). He said that he had "minimized this effect as much as possible" (Rubin, 1970, p. 124), and according to him, this spatiality is unlike any other kind of three-dimensional illusionism as it appears in art: "the space in a picture is a space in which two-dimensional forms seem, thanks to a trick, three-dimensional, in such a way that the space actually perceived is located in between. And this 'in between' is a good analogy for my work. I work by moving away from the flat surface, but I don't want to be three-dimensional, at least literally... more than two dimensions, but less than three" (Fried, 1965, p. 5).

In his later writings on this series, he claims to have cautiously examined the possibilities of what he names "working space" (Stella, 1986), which to him explains "the tension between the dual realities that while a painting consists of colours arranged on a flat surface, colours also exert pressures on the eye and on the spaces around them, advancing and receding in an optical push-pull effect so powerful that it feels physical and spatial" (Litt, 2011). Some critics, like Barbara Rose and Rosalind Krauss, claimed he had found a new kind of illusionism, which is completely abstract and not relatable to any classic form of illusion we know from traditional art: "the various colours caused the shapes to have differing visual effects" (Kennedy, 2010, p. 11). In case of the Irregular Polygons series, all forms of depth (illusion) are material bound and thus unambiguous. Rose wrote about these paintings: "[...] Stella combined an amputated partial perspective with unusual contrasts of various commercial pigments, including fluorescent DayGlo paints [...] (Rose, 1967, pp. 214-215)." She then continues, "Through intense colour contrast and perspective, Stella alluded to depth" (Rose, 1975, pp. 214-215), which she claims is a "[...] spatial reading that is immediately contradicted by the absence of the normal apparatus of illusionism, such as overlapping planes and value contrast" (Rose, 1975, pp. 214-215). In 1966 Krauss remarked, upon first viewing the Irregular Polygons, that the juxtaposed colours add to the illusion of depth: "one colour could cast a shadow on the other, thereby insinuating depth and denying the two-dimensional surface" (Kennedy, 2010, p. 93), this way "the colours seem stacked up or telescoped" (Krauss, 1968, pp. 41-42). In contrast, art historian and art critic Michael Fried claimed that these series of paintings are illusion-less (Fried, 1966), while critic and artist 
Donald Judd, claimed that the medium 'painting' is inseparably connected with illusion and therefore both abstract and classic (pictorial) forms of illusion are indistinguishable (Judd, 1965). Up till this day, these polemics on how to categorize these artworks remain unsolved and still influence current art historical debates (Lejeune, 2015; Van Gelder, 2004).

\subsection{Daylight Fluorescent Colours vs. Conventional Colours}

Because we focus on two different types of colour that are related to a specific kind of pigment, it is important to understand the main differences in visual characteristics of these materials. Paint consists of a (combination of) pigment(s), mostly a ground inorganic material, emulsified in a medium. The colours in art works appear through absorption and reflection of these pigments. Daylight fluorescent colours, on the other hand, are organic pigments, in which a dye is bound to an organic polymer and as a substance grounded into pigment (Streitel, 2009). These pigments absorb energy of the shortwavelength range of the visible light and reemit this energy over a narrow range of longer-wavelength light. When observing such a fluorescent paint layer, one not only distinguishes colour, but it also appears as if the material glows by itself. This is because the pigment converts more light than was originally present in the light of the surrounding area, which makes it appear as a very bright, radiating colour (Livingstone, 2002).

\subsection{Phenomenological Analysis of the Experience of Depth Caused by Interactions of Fluorescent and Conventional Colours}

The descriptions by critics can be placed in two camps: those who claim that the Irregular Polygons paintings do not provoke any illusion and those who speak of their new kind of 'abstract' illusionism. In an attempt to adjudicate between both, we investigated mentions of depth effects caused by fluorescence in the writings of other artists and scientists.

In a 1965 column, Floating Blossoms, published in Color Engineering magazine, Angela Little was the first in the literature to address the peculiar behaviour caused by the combination of fluorescent and conventional colours. This phenomenon first grabbed her attention when she was confronted with Andy Warhol's 'Blossoms' (Flower) silkscreen paintings. She experienced the fluorescent flowers as strongly protruding: "When I first became aware of the painting [Note 2], I was not looking directly at it, but was walking towards another one on a wall at right angles to it. Suddenly out of the corner of my eye, I had an impression of movement that left me a bit dizzy. The flowers were leaving the canvas! I turned then to the flowers and much to my amazement, the two lower magenta figures were suspended in mid-air, a considerable distance from the plane of the painting, the red one was similarly suspended, not in 
the same plane, but behind the magenta ones, and the yellow one remained on the canvas. The illusion was so convincing that I almost instinctively tried to pass my hand behind the flowers, but in front of the canvas itself" (Little, 1965, p. 4). In a more recent publication, Exploring Boundaries in Painting Technique, the authors McGlinchey and Pratt describe the visual effect caused by fluorescent and conventional colours in the work of Rosenquist (Note 3) as follows: "(...) Rosenquist used fluorescent paint selectively so that the different elements in the composition intensely compete for the viewer's attention" (McGlinchey and Pratt, 2000, p. 9). In short, when fluorescent colours are combined with conventional ones, they disturb the colour harmony, grab the viewers' attention and when carefully observed, they tend to be pulled out from the surface. However, some viewers experience no depth at all in such a colour situation and to others the reverse effect might happen: "my sister claimed that she could see the flowers receding into the canvas and my mother soon after agreed that she too saw them receding" (Little, 1965).

As a trained painter, the first author distinguishes the change of colour hierarchy when fluorescence is present. When non-fluorescent colours are combined in a work of art, their hue, saturation and lightness determine how an observer sees them in relation to one another. If we put a high-key yellow in a dark blue square, the yellow will be most visible and appear much brighter than when surrounded by lighter colours. To create such a simultaneous contrast effect (Itten, 1970), the rules are simple: when surrounding a light colour by a dark colour, the light one will appear lighter and vice versa. However, when any daylight fluorescent colour (yellow-orange-pink-red-green-blue) is surrounded by a conventional one, it will always be most visible and cause the surrounded conventional colours to 'grey out' because of the differences in vividness. This way, the conventional colours will make the fluorescent ones appear to be even more intense. In general, one sees a global layer of greyish hues and some strongly contrasting, fluorescent colours. Artist and colour engineer Herbert Aach (1923-1985) commented on the Warhol-blossomsphenomenon: “(...$)$ the green was of relative low intensity, more grey than not. Whereas the pink Day-Glo [what Little named 'magenta' in her description] is of such high intensity that the blossoms seemed to jump off the canvas" (Little, 1966). According to him, this optical phenomenon is "a function of Chroma contrast" (Little, 1966). Later, in an article in Leonardo (1970), Aach gives another good illustration of a hierarchical transition because of contrast effects between conventional and fluorescent colours: "Have you ever seen uncut, chemically pure Cadmium orange look like dirty ochre? Just place it into a field of fluorescent green. Unbelievable, it does appear ochre. Now I know how Turner (1775-1851) made paintings by his contemporaries look as though they were made with washed out colours and how to make a Hofmann (18801966) or a Lanskoy (1902-1976) look like weak tea, one uses fluorescent pigments. It is remarkable how quickly the eye adapts itself to the intensity of 
fluorescent colours and how one's colour perception is increased rather than decreased" (Aach, 1970, p. 136).

Beside the hierarchical influences, there is another difference related to brightness, caused by the emission of light, which strengthens the appearance of the colour of fluorescent pigments, although the percentage of pigmentation in such a transparent, luminescent paint layer is significantly lower than in the conventional ones. From some of the above-mentioned descriptions of critics and scientists, it seems that fluorescent colours cause what we can call an 'alienating' effect, in which colours, by themselves, project into or from the surface. Aach was amazed that these colours could create "spatial illusions regardless of perspective clues" (Aach, 1970). This effect has played a major role in his work: "I do not provide any spatial clues outside of color. I use neither outline drawing, nor internal scale relationships nor angular perspective. Therefore, I am surprised when people tell me that either they feel compelled to walk into one of these paintings or they have the sensation of being pushed backwards" (Aach, 1970, p. 136).

In order to better understand this specific colour depth-effect, we should first consider the theory of cool and warm colours. Artists of all times have used this rule to create the illusion of landscapes and call the fact that cool colours recede and warm colours advance, 'atmospheric perspective'. In 1868 Bruecke first described the stereoscopic effect of colours as 'chromostereopsis', which means that when pure, extreme spectral colours like blue and red are observed in a rather controlled situation (side by side in a dark surrounding), the blue hue can appear as receding and the red as protruding (Vos, 2008). They appear at different depths due to 'chromatic aberration', in which the prismatic shifts of the edges go in opposite directions in the two eyes.

However, beside the fact that the conventional warm/cool colour rule provides a certain experience of depth, in the case of fluorescent colours, the first author experienced a reinforcement of this effect because the emitted light seems to optically dissolve its surface. In other words, the fluorescent effect distorts the visibility of the texture of the coloured surface (the canvas) and creates the impression that one is looking into a transitive coloured space.

Together, all described optical effects cause an illusion of spatiality, which, especially in combination with conventional hues, appears to some as strongly protruding and to others as strongly receding (Note 4). All the abovementioned descriptions overlap strongly, in the sense that a depth experience is common. Based on this, our hypotheses were formulated.

\subsection{Research Questions and Hypotheses}

With this experiment, the experience of depth caused by the combination of fluorescent and conventional colours was examined. First of all, we wanted to 
find out if fluorescent colours were experienced as more receding or protruding than conventional colours in the same design. Secondly, we wanted to study whether participants still experienced colour depth when all fluorescent colours were replaced with their conventional variants. Finally, we wanted to determine whether there were differences in results when looking at participant characteristics (artist, art historian or laypeople).

Taking into account all described phenomenological observations above, we hypothesized that the majority of participants would give all fluorescent colours stronger (more protruding or more receding) depth ratings than the conventional ones. Bearing in mind the warm/cool colour rule, we expected the fluorescent effects to be multiplicative to this rule. Namely, more strongly protruding experiences for the long wavelength fluorescent colours when compared to their conventional counterparts and more receding experiences for short wavelength fluorescents in contrast to conventionals.

\section{Method}

The illusory depth in Irregular Polygons paintings is not only caused through colour interactions, but also through form and surface materiality characteristics like gloss vs. matt surface, blurred edges, texture of the canvas, and the number of paint layers. This experiment only focuses on colour interactions, however. We therefore isolated the colour combinations of four different paintings of this series. The method, choice of the works, the design and execution of the stimuli will be explained in this section.

\subsection{Design Stimuli}

This experiment is based on four works from the Irregular Polygons series: Effingham I, Chocorua IV, Union I and Sanbornville III. These paintings were each taken from the different sub-series of the entire group. We chose them because of their different colour combinations. All of them consist of one or two fluorescent colours, together with two or three conventional colours (Note 5). In total, five different fluorescent colours were investigated (fluorescent yellow-fluorescent pink-fluorescent red-fluorescent green- fluorescent blue) in combination with a variety of conventional colours (yellow-orange -pink-red-grey-(dark)green-(green-)blue-pistachio-cream yellow-ochre).

Because this experiment focused on the experience of colour depth, we developed a design in which all colours were aligned in strips, to cancel out depth caused by form as much as possible. Both the position and the proportions of each coloured zone referred to the original work. In the overview below (Fig. 1) a list is given of the four works and the designs derived from them, including the names of the colours used in each design, from left to right. The 
first design is the original; its colour sequence was based on the relationship of the colours in the original artwork. Each original was compared with a conventional variant, which means that all fluorescent colours were replaced by similar conventional hues. In order to measure the impact on the depthexperience caused by the position of the colours of the original, we opted for one or two extra variants. In these variants, the colours were swapped or an extra fluorescent hue was added by replacing a conventional one.

First, we will have a look at the designs based on Effingham I. The central area of this painting consists of a large orange plane that is partly unbounded and partly bound by a fluorescent blue band. This band extends by curling around a smaller fluorescent yellow shape. The first and second design of Effingham I were the original and the conventional variant, in which the (fluorescent) yellow was placed in between two (fluorescent) blue strokes of the same hue, followed by a large orange panel. We added two more variants to this series. The first was the same as the original, except for the fluorescent yellow panel, which was replaced by a conventional yellow. For the second variant, panels 1 and 3 were fluorescent yellow, with an orange panel in between and at the right end a large fluorescent blue panel.

Besides our main interest in the differences between the original and the conventional variant, we were also interested in several specific colour relations. For this series, we wondered whether the depth experience of fluorescent blue increased when combined with a conventional yellow, instead of a fluorescent yellow [comparing the results of fluorescent blue from designs 9 and 5 (both contain fluorescent yellow, but in different positions) with design 1 (conventional yellow)]. Also, the other way around: did yellow appear differently when combined with fluorescent or conventional blue [comparing the results of design 13 (blue) and 1 (fluorescent blue)]? Finally, did fluorescent yellow obtain different ratings when its position changed (comparing designs 9 and 5)?

In Chocorua IV, the fluorescent red triangle is trapped in a grey surrounding band. This way, the fluorescent red does not touch the yellow and the dark green zone. The grey band is next to the yellow, but does not touch the dark green zone. Beside the grey band, the yellow stroke touches the green shape. For the first design, a medium-sized fluorescent red panel was placed in between two small grey strokes, followed by a yellow band and a large dark green panel. The second design was the conventional variant of the original. There were two more variations: the first was the same as the original, but the yellow colour was made fluorescent. In the second variant the fluorescent red was switched with a dark green-coloured panel.

In this series of designs, our first interest was the difference in ratings between the original and the conventional variant (comparing designs 14 and 7). We also wanted to see if there were changes in ratings when both red and 
yellow were fluorescent in the same design [comparing design 14 (yellow) with designs 11 and 3 (both contain fluorescent yellow, but in different positions)]. Did we get a difference between designs 11 and 3, which both consisted of the same colours, but were positioned differently? In this case, a fluorescent yellow and a large fluorescent red panel were put next to each other. The two grey panels remained in the same position through all four designs. We also wondered whether they did appear differently when fluorescent red was turned into conventional red [comparing designs 14 and 11 (both contain fluorescent red, but in different positions) with 7 (red)] or when the fluorescent red panel was switched with a dark green one [(comparing design 14 and 11 (both contain fluorescent red, but in different positions) with 3 (dark green)].

The colours in Union I all interact with each other: the pistachio and the fluorescent pink barely touch. For the original and conventional design, we did put the large (fluorescent) pink surface next to a medium sized, ochre panel, ending with a pistachio band. For this series, only one variant was added because of the limited number of panels. Beside the differences between the original and the conventional variant (comparing designs 6 and 10), it was interesting to also study the effect of the fluorescent pink in between the two conventional colours (comparing design 6 and 2).

Sanbornville III consists of a large, half-open, cream yellow form that is partly delineated by a grey-blue band, which surrounds a triangle shape and a parallelogram. Inside the triangle, a fluorescent green band surrounds a cream yellow smaller triangle. In the parallelogram, this structure is repeated, but the colours are inverted. The first two designs were based on the colours of the original (the second with conventional variants). For the two variations, the colours were repositioned: in the first, the grey blue panels were swapped with cream yellow ones and for the second, the cream yellow panels remained the same as in the first variant, but the fluorescent green panel was swapped with the grey-blue one.

As in the other series, our first interest was to find out whether there were differences in ratings between the original and conventional variants (comparing designs 8 and 4). We were also interested to see if there was a change in ratings when fluorescent green was surrounded with cream yellow instead of grey-blue (comparing designs 8 and 12) and whether the changed position of fluorescent green influenced its appearance (comparing designs 8 and 15).

\subsection{Execution of the Designs}

To simulate the colour effects of the artworks and in order to maximally avoid distractive factors like texture, gloss and thickness, we decided to screenprint these designs on large-scale paper $(720 \times 1020 \mathrm{~mm} ; 300 \mathrm{~g}$ Bristol $)$ 
with fluorescent and conventional inks of the brand Publivenor (Note 7). The first author made prints that matched the colours of the original as closely as possible. In order to determine the colours, she based them on several photographs of the artworks, combined with information provided by gallerists and museums that helped us determine which colours were fluorescent. The latter is not always easy to distinguish, because of the impossibility of capturing the fluorescent effect in a printed reproduction (Note 7), so she often had to ask them to check the colours in the actual paintings using UV light.

\subsection{Participants}

The sixty participants were divided in three groups: twenty artists (who have a degree in art and who are professionals in the field), twenty art historians (who have a university degree in art history and who are not artists) and twenty laypeople (with no art-related background). Each group consisted of the same number of men and women. They were all screened in advance for colour blindness using the Ishihara test (Note 8). A questionnaire that was filled out after the experiment revealed that all art historians, except one, were familiar with the work of Frank Stella. Forty percent (most of them experts in modern and contemporary art) claimed they had strong knowledge of his entire oeuvre. Only a few knew about his use of fluorescent paints.

For this experiment, it was interesting to compare the results of artists with art historians, artists with laypeople, and art historians with laypeople, i.e., according to presumed susceptibility to knowledge-induced perceptual biases, or in other words, whether we could find proof of a stronger influenced and shaped perception due to previous knowledge and predictions (Gregory, 1980, 1990). On the one hand, we wanted to find out if the results of the $40 \%$ of art historians who knew Stella's (fluorescent) artworks differed from those of the others. On the other, we wondered whether the ratings of 'trained' artists differed from the other groups.

During their education, most artists learn how to create the illusion of depth in a two-dimensional plane, through learning different perspective techniques, one of which is specifically colour-related: atmospheric perspective. Psychologists like Edwards and Vos both acknowledge the influence of training and prior knowledge on the experience of colour depth perception: "Artists, indeed, may succeed in their attempts to use colour as indicative of distance because many of them have been trained to this belief, and will "see" or interpret according to their training" (Edwards, 1955). Knowing this, we hypothesized that artists would see more depth in both conventional and fluorescent colour than laypeople. As laypeople, the group of art historians also did not enjoy a practical art education. As non-practitioners, the art historians nevertheless benefited from extensive exposure to and analysis of art images. Because artists are in 
close communication with the art historians "the story has apparently found its way into art history as an accepted theory of depth perception through colour (Vos, 2008, p. 140)." During their study and in their profession, art historians learn to 'simulate' the artists' experience from a more theoretical point of view, without enacting it. In this case, we hypothesized that the art historians' experience would be more or less the same as the artists'.

\subsection{Task and Procedure}

The experiment took place between 11 a.m. and 4 p.m. in a space with ample natural light at the Academy of Berchem and at the University of Leuven (Fig. 2c). The sixty participants were asked to determine the perceived depth of different parts in all fifteen designs by filling in a questionnaire (Fig. 2b). All participants had to rate each coloured panel on the scale: -3 (extremely), -2 (strongly), -1 (slightly) receding; 0 surface (no depth); 1 (slightly), 2 (strongly), 3 (extremely) protruding. After each design, the participant had a short 'normalization break' (around $30 \mathrm{~s}$ ) during which she had to stare at an average grey surface. All designs were ordered to ensure that participants would never see two designs of the same series consecutively. The stimuli were bound together in three groups of five for counterbalancing $(\mathrm{A}=$ stimuli $1-5, \mathrm{~B}=$ stimuli $6-10, \mathrm{C}=$ stimuli $11-15$; different orders: $\mathrm{A}-\mathrm{B}-\mathrm{C}$; $\mathrm{B}-\mathrm{A}-\mathrm{C}$ and $\mathrm{C}-\mathrm{B}-\mathrm{A})$. The order number of each design can be found in the overview

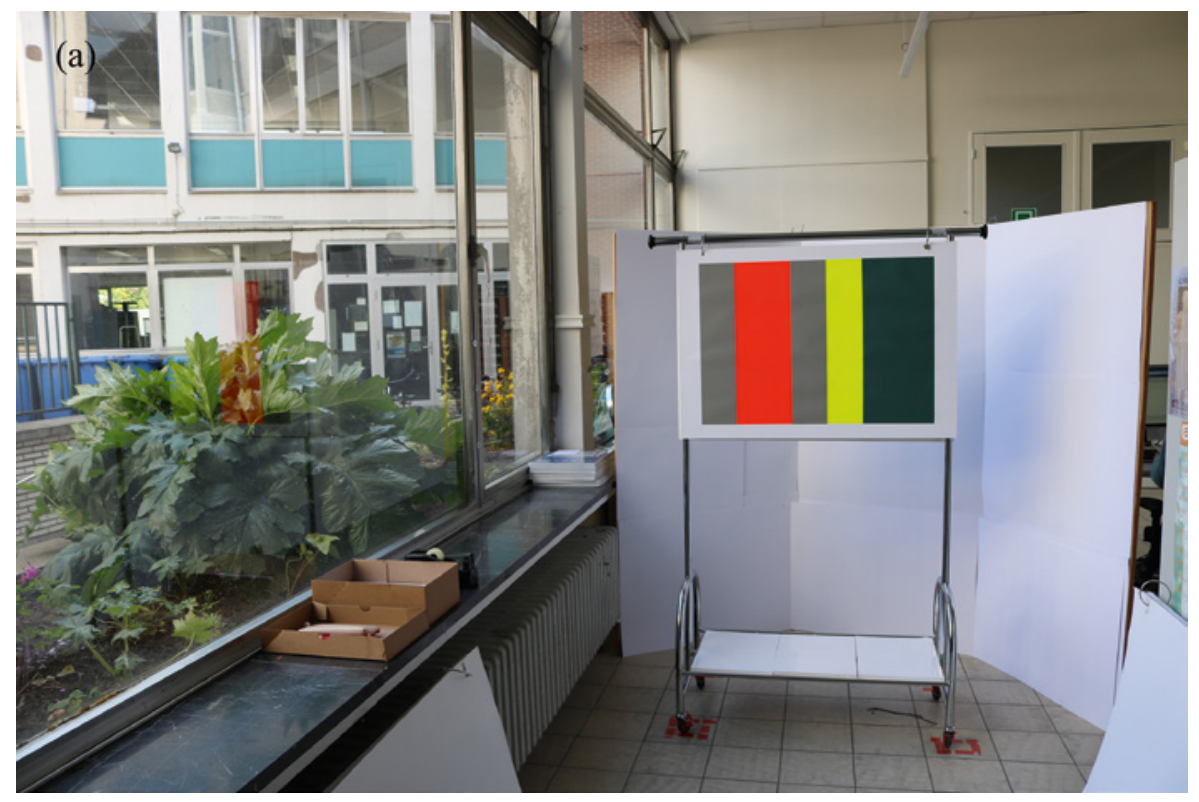

Figure 2. (a) Impression of the setup of the experiment in the Academy of Berchem ( $\odot$ Stefanie De Winter); (b) impression of a participant observing the stimulus during the experiment (C Stefanie De Winter); (c) an example of the questionnaire (see Appendix for enlarged version). 


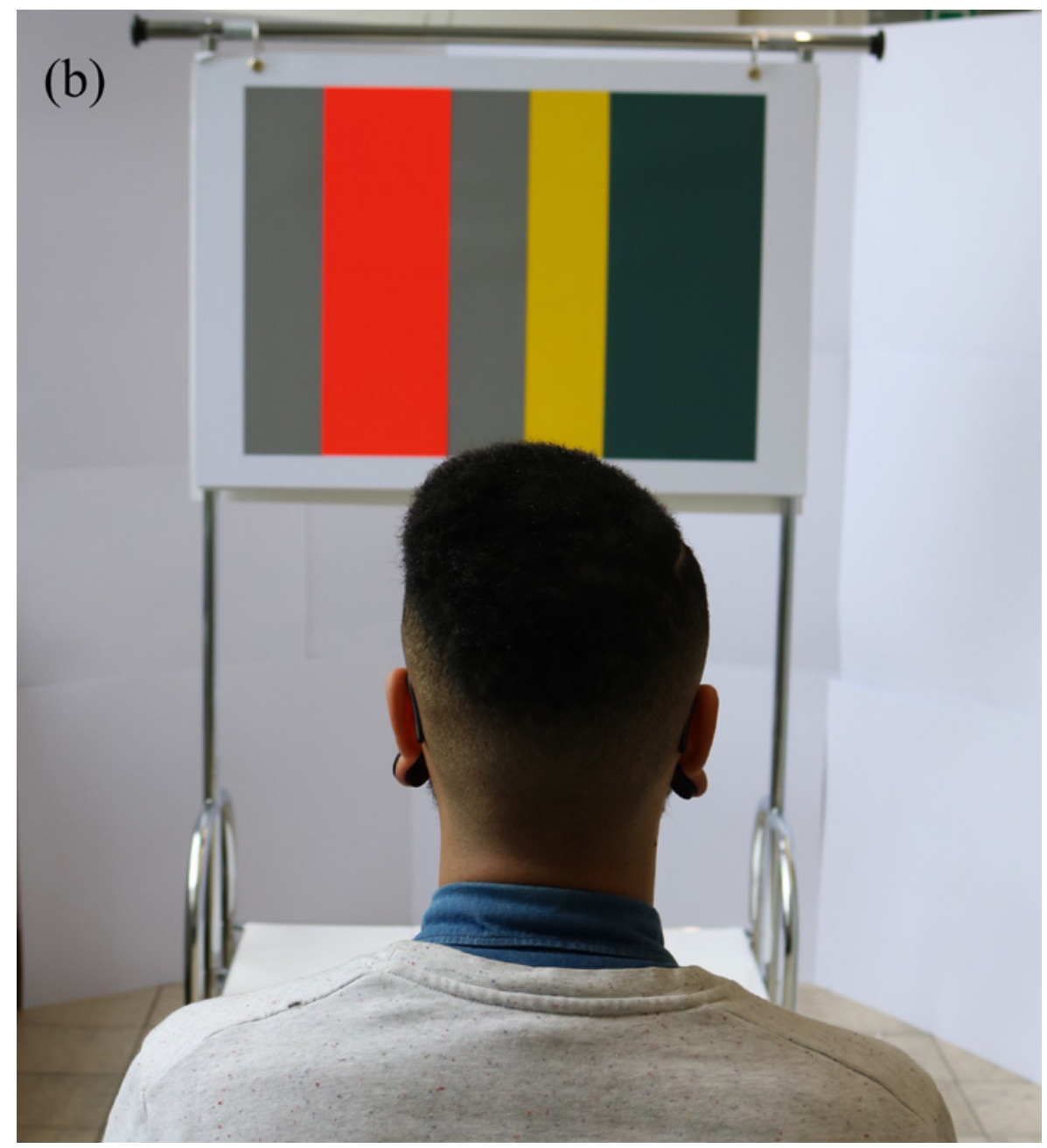

Figure 2. (Continued)

above (Fig. 1). Half of each group started with the last design (they ran the experiment backwards). The distance between the stimuli and the participant was $2.5 \mathrm{~m}$, to exclude the interference of small deformations. The stool on which they sat was adjustable to ensure that each participant's eyes would be in the middle of the panel.

\section{Results}

In this section the results of this rating-based experiment will be discussed. As mentioned before in subsection 2.4, participants had to report the perceived depth of all coloured panels (on a scale ranging from -3 to 3 - see Appendix) 


\section{(c)}
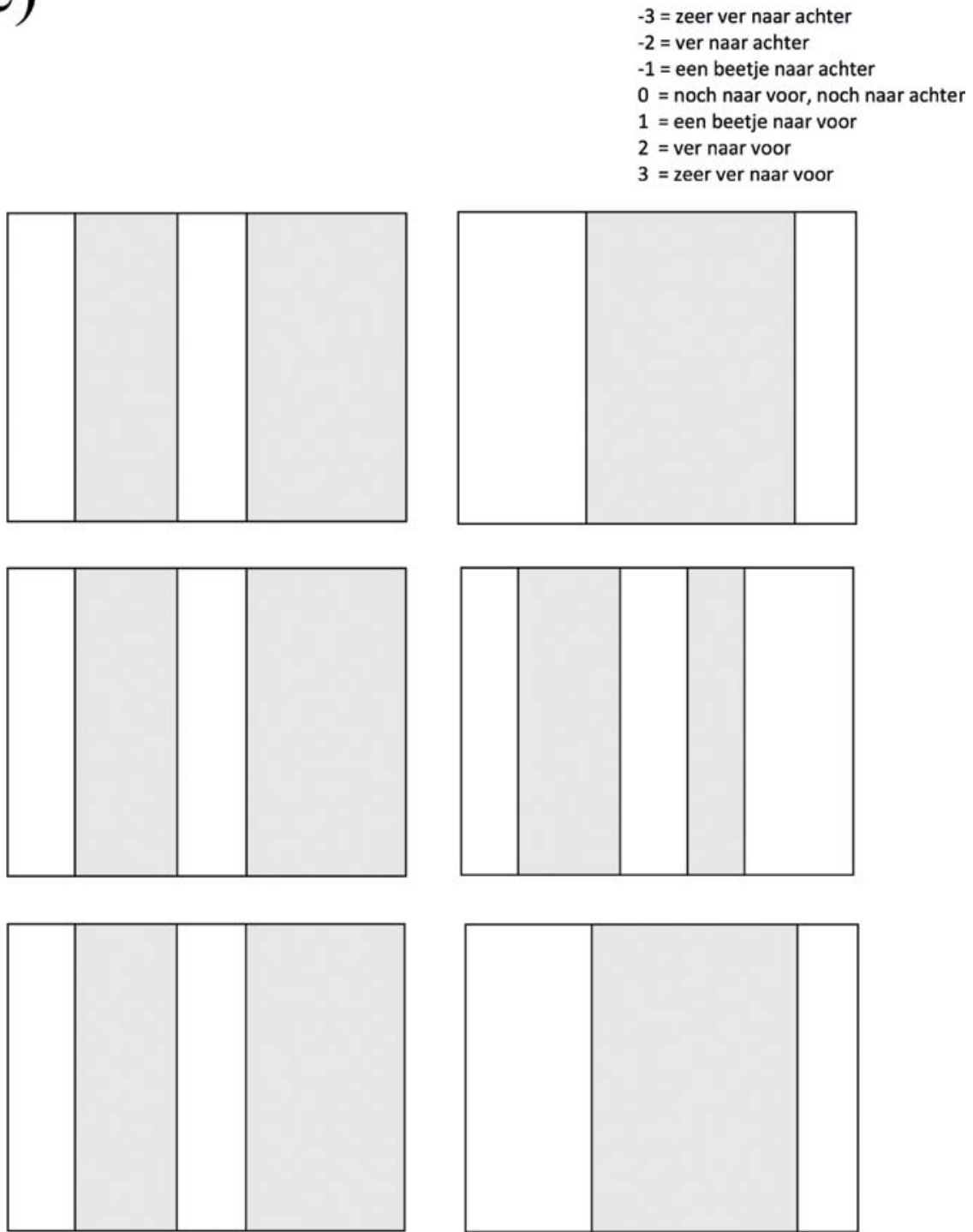

Figure 2. (Continued)

of each design. Based on the phenomenological descriptions from the introduction, we hypothesized that all fluorescent panels would generate more depth than the conventional colours. To provide an overview of both colour groups, we will start with presentating some general analyses of the mean depth ratings of both colour groups (Figs 3-5), followed by the mean depth ratings of all colours separately (Fig. 6). As an addition, the proportion of signed ratings of each colour will be shown, in order to visualize the differences in percentages 


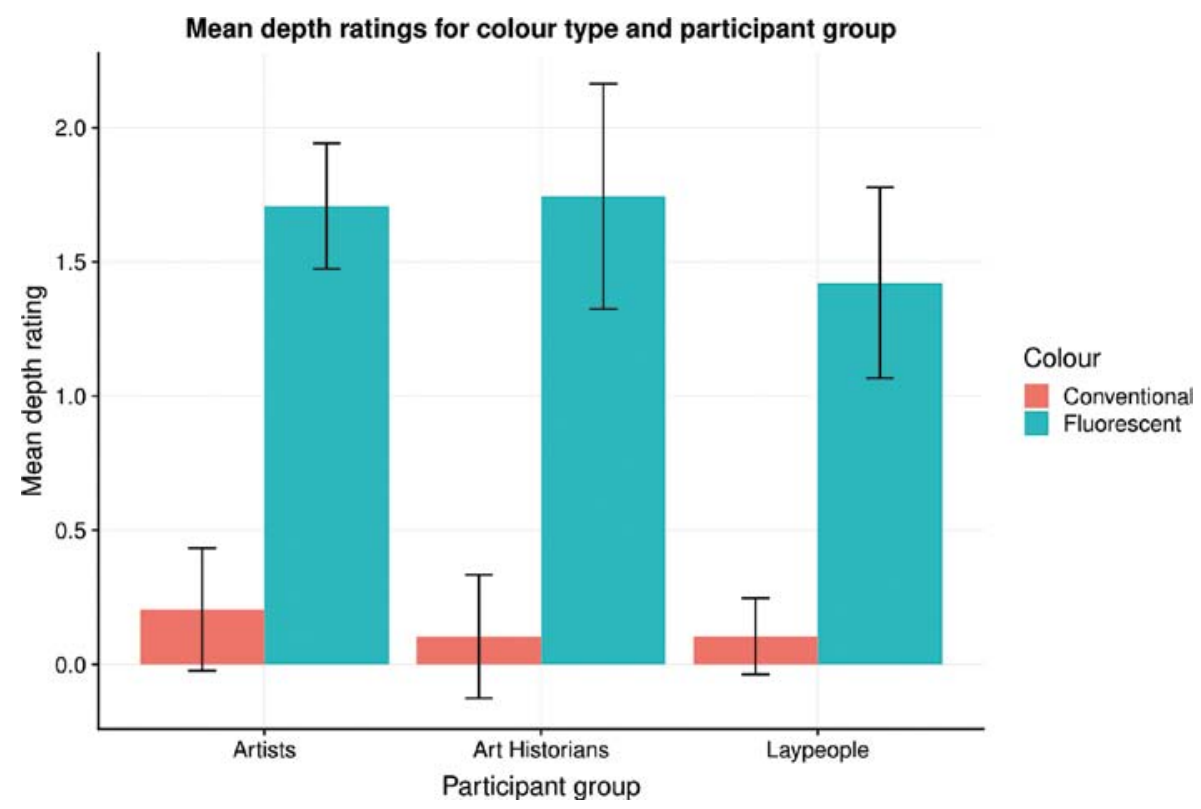

Figure 3. Mean depth ratings of all fluorescent and all conventional colours, for each participant group. Error bars indicate $+/-2$ SEM.

(the number of negative, positive or zero ratings per colour) of each participant group (Fig. 7). We also look at whether the fluorescent effect affects the perceived depth differently for warm and cool colours (Fig. 8 below). In the last part of this section, we will look at the results of all colours per design group separately (Figs 9-12). This will provide insight in the specific colour interactions: how they are influenced by the positioning between colours and by whether they are fluorescent or not. The three participant groups will again be shown next to each other to facilitate comparison. We will end this section by exploring three matrices (Fig. 13) (based on the design series of Effingham I, Chocorua IV and Sanbornville III), in which all three participant groups and their number of different ratings of the same colour in the same design, caused by contrast effects, will be compared. All data and code for the analyses reported can be found at: https://osf.io/k3u46/.

\subsection{Mean Depth Ratings of the Two Types of Colour}

Figure 3 visualizes the mean depth ratings of the fluorescent and conventional colours for each type of participant, collapsed across specific design colours (see Table 1 for means and standard deviations of the depth ratings). This figure provides an insight to the central research question of this paper, whether or not fluorescent colours receive different depth ratings compared 


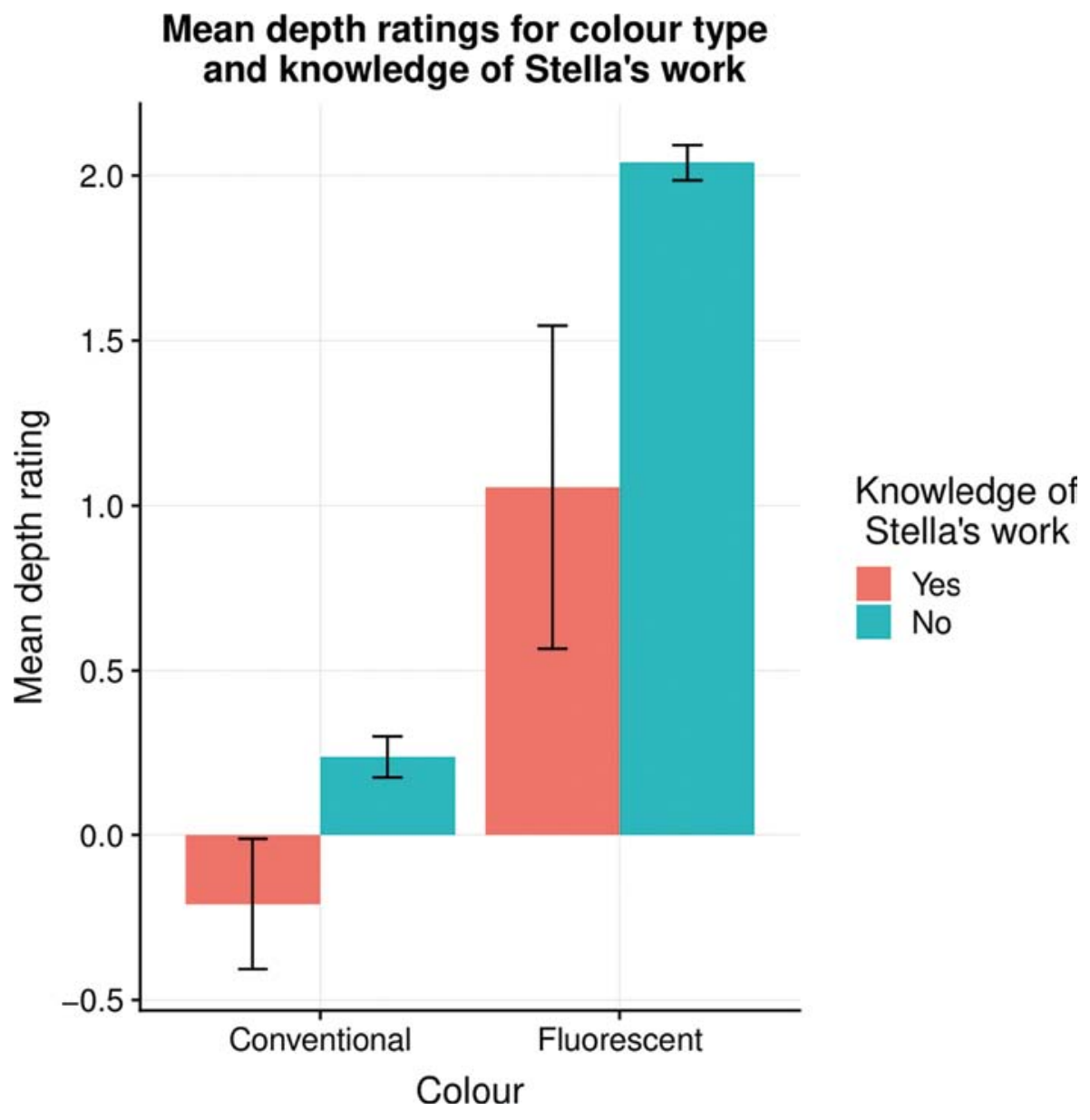

Figure 4. Mean depth ratings of all fluorescent and all conventional colours, for art historians only and as a function of their knowledge of Stella's work. Error bars indicate +/- 2 SEM.

to normal colours. In general, it is quite clear that fluorescent colours differ considerably in their mean depth rating. Indeed, on average fluorescent colours were seen as significantly more protruding than the conventional ones (see Table 2, row 2 for the outcome of the statistical test). Overall, the laypeople rated the fluorescent colours as slightly less protruding, while the artists assigned slightly more depth to the normal colours, compared to the other participant groups. The art historians rated depth caused by fluorescent colours the same as the artists and depth caused by conventional colours the same as laypeople. Nevertheless, these subtle interactions between participant group and colour type did not reach conventional levels of statistical significance (see Table 2 for the absence of an interaction effect between participant group and colour). 


\section{Mean depth ratings for luminance and colour type}

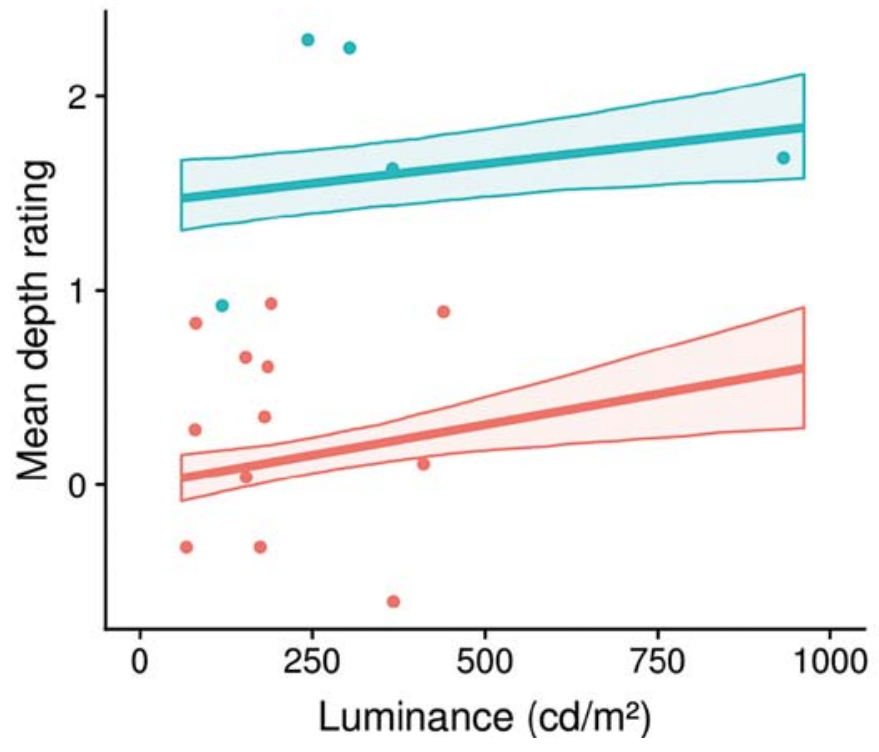

Colour

- Conventional

- Fluorescent

Figure 5. Mean depth ratings of all fluorescent and all conventional colours, for each colour separately. Lines indicate the fitted regression line of the model summarized in Table 4. Shaded areas depict the $95 \%$ confidence interval around the fitted regression lines.

(a)

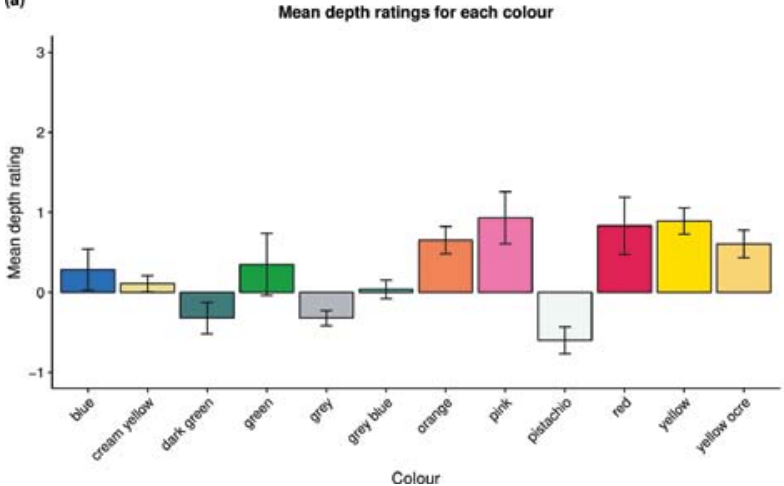

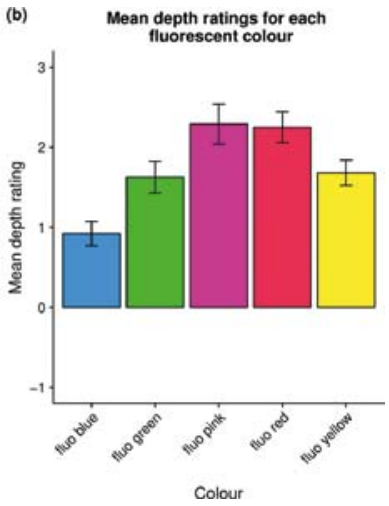

Figure 6. (a) Mean depth ratings for all conventional colours; (b) mean depth ratings for all fluorescent colours. Error bars indicate +/- 2 SEM.

\subsubsection{Does Knowledge of Frank Stella's Work Modulate the Effect of Fluorescence on Perceived Depth?}

As highlighted in subsection 2.3, 40\% of art historians claimed to have strong knowledge of Frank Stella's entire oeuvre. In this additional analysis, we ask whether knowledge of Stella's work modulates the effect of fluorescence on 

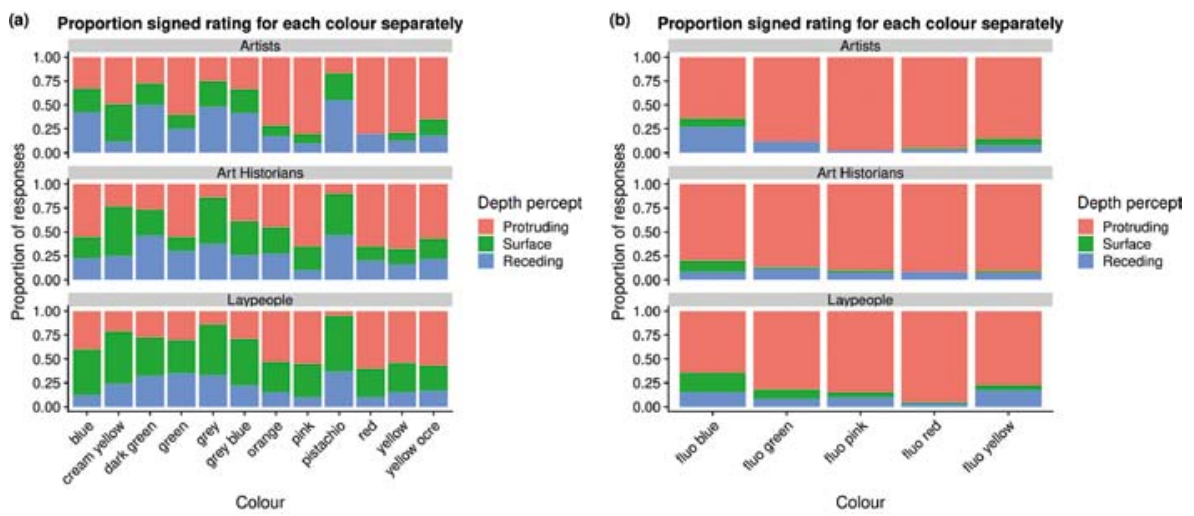

Figure 7. (a) The proportion signed rating for each conventional colour separately, divided in three groups (artists, art historians \& laypeople); (b) the same, but of each fluorescent colour separately.

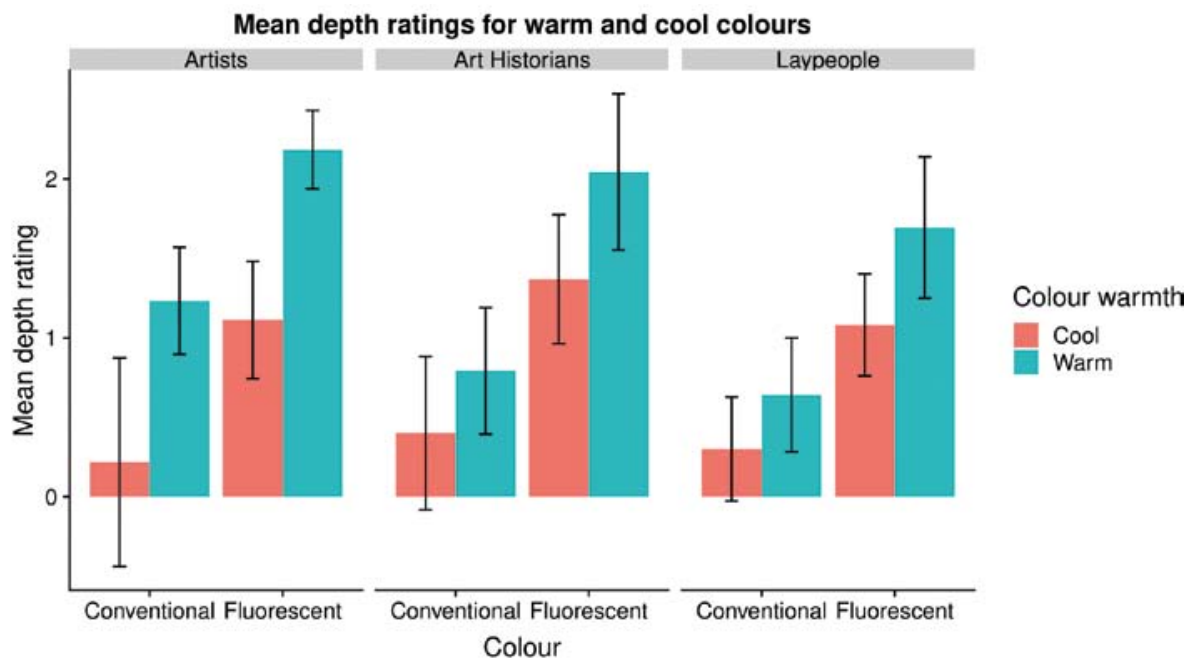

Figure 8. Mean depth ratings of warm and cool floors for fluorescent and conventional colours and all participant groups. Error bars indicate $+/-2$ SEM.

perceived depth within the group of art historians. Figure 4 depicts the same data as in Fig. 3, but now for only the art historians, and broken down by knowledge of Stella's work. As can be derived from this figure, art historians who had knowledge of Stella's work on average showed less strong depth ratings (i.e., more receding compared to the other art historians). This was confirmed by the statistical analysis reported in Table 3. A main effect of knowledge emerged together with the (expected) main effect of colour. Nevertheless, 


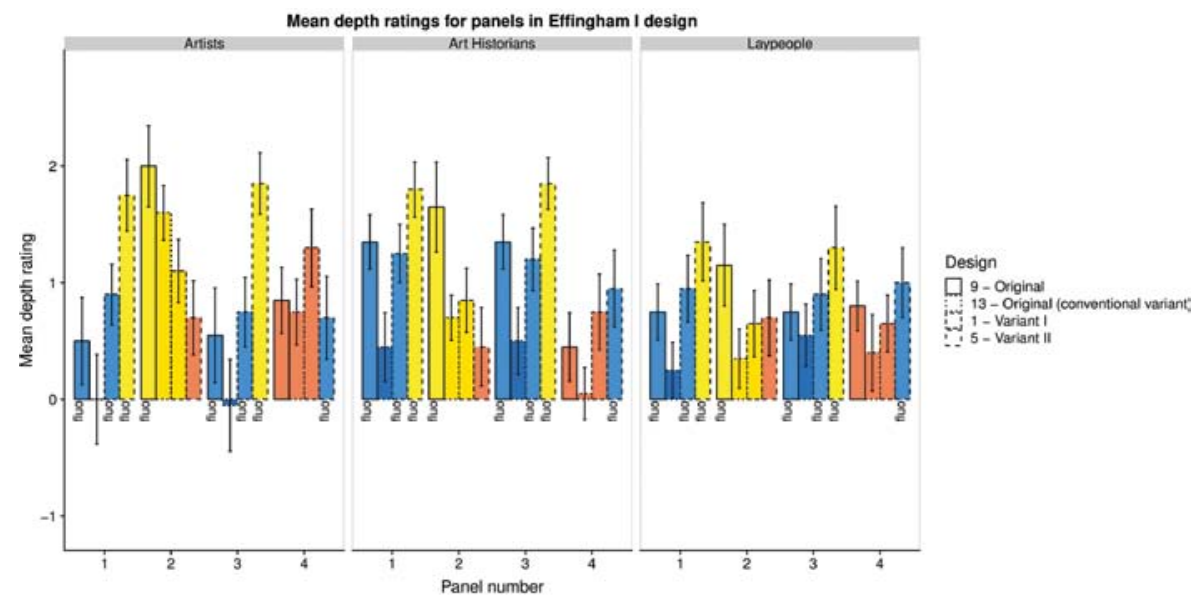

Figure 9. Mean depth ratings for all panels in the Effingham I design group.

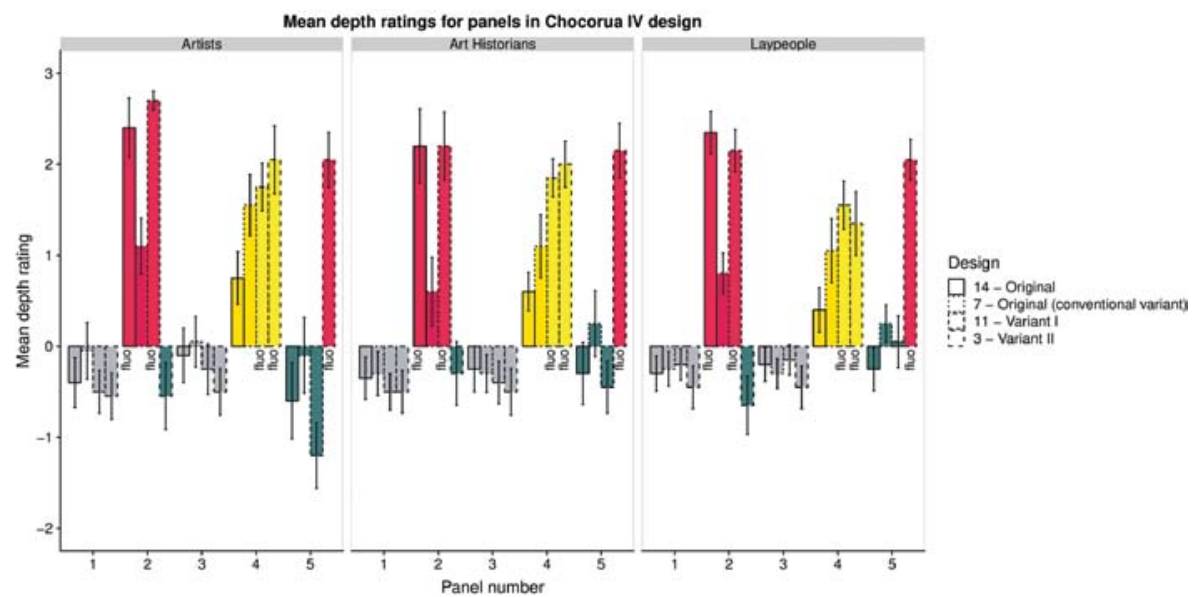

Figure 10. Mean depth ratings for all panels in the Chocorua IV design group.

this main effect of knowledge did not interact with the fluorescence effect, putatively indicating that these art historians adjusted their ratings because they knew of Stella's usage of fluorescent colours compared to other art historians.

\subsubsection{Do Luminance Differences Between Colours Explain the Effect of Fluorescence on Perceived Depth?}

Fluorescent colours were generally brighter $\left(M=393 \mathrm{~cd} / \mathrm{m}^{2} ; \mathrm{SD}=315 \mathrm{~cd} / \mathrm{m}^{2}\right)$ compared to conventional colours $\left(M=207 \mathrm{~cd} / \mathrm{m}^{2} ; \mathrm{SD}=128 \mathrm{~cd} / \mathrm{m}^{2}\right)$. A relevant question to address is thus whether the effect of fluorescent colours on perceived depth is not due to the luminance of the stimuli, rather than their fluorescence. To address this question, we ran a linear mixed-effects model on the 


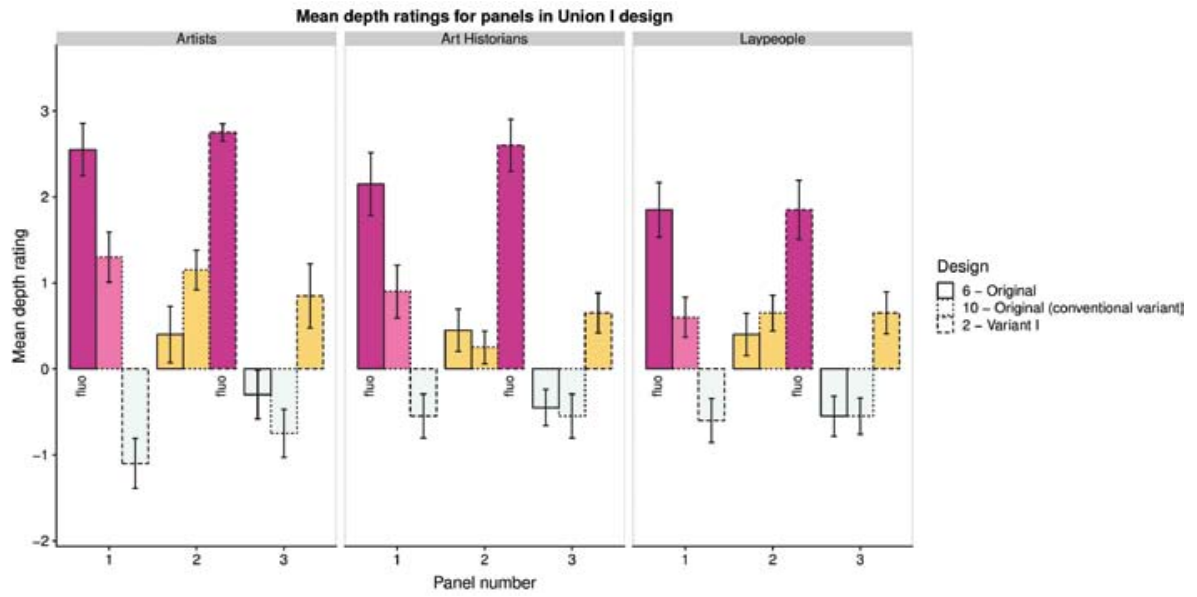

Figure 11. Mean depth ratings for all panels in the Union I design group.

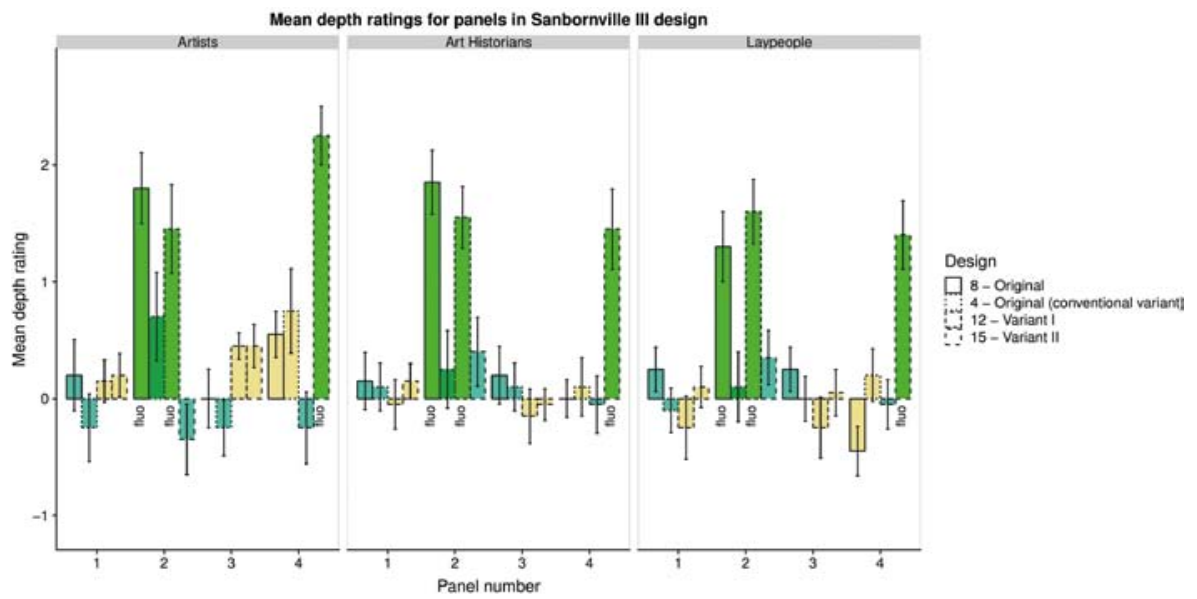

Figure 12. Mean depth ratings for all panels in the Sanbornville III design group.
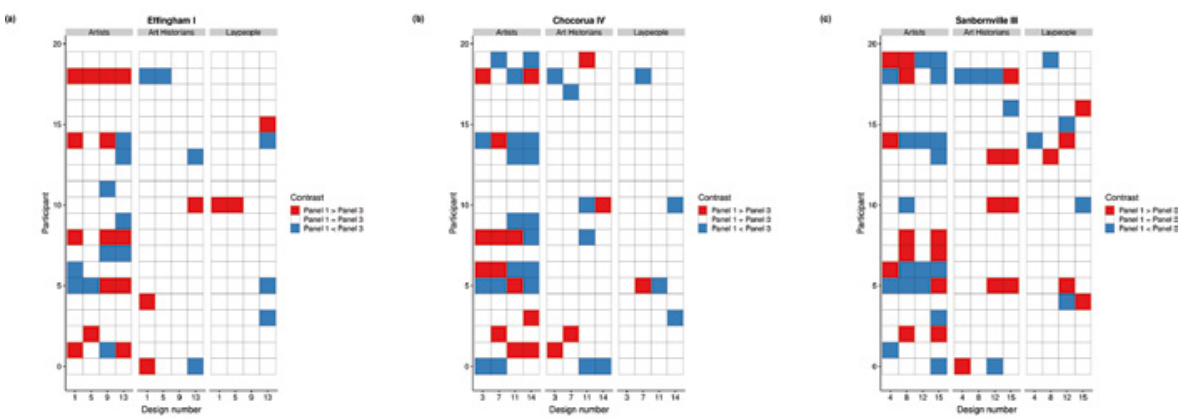

Figure 13. (a) Matrix of visualized contrast effects for Effingham I; (b) matrix of visualized contrast effects for Chocorua IV; (c) matrix of visualized contrast effects for Sanbornville III. 
Table 1.

Means and standard deviations for depth ratings.

\begin{tabular}{|c|c|c|c|c|}
\hline \multirow[t]{3}{*}{ Participant group } & \multicolumn{4}{|c|}{ Colour } \\
\hline & \multicolumn{2}{|c|}{ Conventional } & \multicolumn{2}{|c|}{ Fluorescent } \\
\hline & $M$ & SD & $M$ & $\mathrm{SD}$ \\
\hline Artists & 0.20 & 0.51 & 1.71 & 0.52 \\
\hline Art historians & 0.10 & 0.51 & 1.74 & 0.94 \\
\hline Laypeople & 0.10 & 0.32 & 1.42 & 0.80 \\
\hline
\end{tabular}

$M$ and SD represent mean and standard deviation, respectively.

Table 2.

Results of repeated measures ANOVA for depth ratings in function of participant group and colour.

\begin{tabular}{lccrrr}
\hline Predictor & $\mathrm{df}_{\text {Num }}$ & $\mathrm{df}_{\text {Den }}$ & \multicolumn{1}{c}{$F$} & \multicolumn{1}{c}{$p$} & $\eta_{\mathrm{g}}^{2}$ \\
\hline Participant group & 2 & 57 & 0.82 & 0.443 & 0.02 \\
Colour & 1 & 57 & 231.60 & $<0.001$ & 0.59 \\
Participant group $\times$ Colour & 2 & 57 & 0.92 & 0.405 & 0.01 \\
\hline
\end{tabular}

$\mathrm{df}_{\mathrm{Num}}$ indicates degrees of freedom of the numerator; $\mathrm{df}_{\text {Den }}$ indicates degrees of freedom of the denominator; $\eta_{\mathrm{g}}^{2}$ indicates generalized eta-squared.

Table 3.

Results of repeated measures ANOVA for depth ratings in function of colour and knowledge of Stella's work.

\begin{tabular}{lccrrr}
\hline Predictor & $\mathrm{df}_{\text {Num }}$ & $\mathrm{df}_{\text {Den }}$ & \multicolumn{1}{c}{$F$} & \multicolumn{1}{c}{$p$} & $\eta_{\mathrm{g}}^{2}$ \\
\hline Knowledge & 1 & 18 & 7.90 & 0.012 & 0.20 \\
Colour & 1 & 18 & 68.74 & $<0.001$ & 0.62 \\
Knowledge $\times$ Colour & 1 & 18 & 1.55 & 0.229 & 0.03 \\
\hline
\end{tabular}

$\mathrm{df}_{\mathrm{Num}}$ indicates degrees of freedom of the numerator; $\mathrm{df}_{\text {Den }}$ indicates degrees of freedom of the denominator. $\eta_{\mathrm{g}}^{2}$ indicates generalized eta-squared.

raw data, predicting participants' depth perceptions based on the luminance of the stimuli as well as whether they were fluorescent or not. To account for variability between subjects, random intercepts and slopes for luminance and colour were included. Table 4 provides a summary of the results of this analysis and Fig. 5 shows the relationship between luminance and perceived depth as a function of the fluorescence of the colour. As is clear from this table and figure, there is a subtle effect of luminance on perceived depth, yet a large part of 
Table 4.

Results of linear mixed-effects analysis for the effect of luminance on perceived depth.

\begin{tabular}{llccc}
\hline Predictor & $B$ & $s$ & $F$ & $p$ \\
\hline Intercept & 0.18 & $0.07-0.229$ & 9.82 & 0.003 \\
Luminance & 0.14 & $0.03-0.25$ & 6.38 & 0.01 \\
Colour & 1.39 & $1.22-1.57$ & 242.44 & $<0.001$ \\
Luminance $\times$ Colour & -.005 & $-0.15-0.04$ & 1.10 & 0.30 \\
\hline
\end{tabular}

$B$ indicates the regression weight. $\mathrm{CI}$ denotes the $95 \%$ confidence interval around $B . F$ and $p$ were calculated according to the method of Satterthwaite.

\section{Table 5.}

Means and standard deviations of depth ratings for each colour separately.

\begin{tabular}{lrl}
\hline Colour & \multicolumn{1}{c}{$M$} & SD \\
\hline Blue & 0.28 & 1.34 \\
Cream yellow & 0.11 & 0.66 \\
Dark green & -0.32 & 1.15 \\
Green & 0.35 & 1.51 \\
Grey & -0.32 & 0.68 \\
Grey blue & 0.04 & 0.76 \\
Orange & 0.65 & 0.88 \\
Pink & 0.93 & 1.26 \\
Pistachio & -0.60 & 0.88 \\
Red & 0.83 & 1.38 \\
Yellow & 0.89 & 0.92 \\
Yellow ochre & 0.61 & 0.82 \\
\hline Fluo blue & 0.92 & 1.00 \\
Fluo green & 1.63 & 1.09 \\
Fluo pink & 2.29 & 1.23 \\
Fluo red & 2.25 & 1.08 \\
Fluo yellow & 1.68 & 1.03 \\
\hline
\end{tabular}

$M$ and SD represent mean and standard deviation, respectively.

the difference in depth perception seems to be explained by the fluorescence of the colours. Based on this analysis, we conclude that luminance indeed plays a role in determining the percept of depth, but its contribution is not sufficient to explain the effect of fluorescence on perceived depth.

\subsection{Mean Ratings of Each Colour Separately}

Figures $6 \mathrm{a}$ and $\mathrm{b}$ visualize the average depth ratings for both types of colour (conventional and fluorescent), this time for each colour separately. Fluorescent 
Table 6.

Means and standard deviations for proportions of depth percepts for conventional colours in each participant group.

\begin{tabular}{|c|c|c|c|c|c|c|}
\hline \multirow[t]{3}{*}{ Participant group } & \multicolumn{6}{|c|}{ Depth percept } \\
\hline & \multicolumn{2}{|c|}{ Protruding } & \multicolumn{2}{|c|}{ Surface } & \multicolumn{2}{|c|}{ Receding } \\
\hline & $M$ & SD & $M$ & SD & $M$ & SD \\
\hline Artists & 0.52 & 0.24 & 0.21 & 0.09 & 0.29 & 0.17 \\
\hline Art historians & 0.43 & 0.21 & 0.29 & 0.13 & 0.27 & 0.11 \\
\hline Laypeople & 0.37 & 0.19 & 0.41 & 0.11 & 0.22 & 0.10 \\
\hline
\end{tabular}

$M$ and SD represent mean and standard deviation, respectively.

blue is the lowest rated fluorescent colour and is experienced as equally protruding as the highest rated non-fluorescent colour, which is pink (Fig. 6a). Fluorescent pink, the highest rated of all colours used in this experiment, was perceived as two and a half times more protruding than its conventional variant.

There is greater variation in the type of depth ratings for colours within the conventional spectrum than for fluorescents (see Table 5 for means and standard deviations of the depth ratings). Indeed, whereas all fluorescent colours were rated on average as protruding, there are a few conventional colours that received a consistently negative mean rating: dark green, grey and pistachio. Others received a mean positive rating: orange, pink, red, yellow, yellow ochre. Grey-blue and cream yellow both received on average more zero ratings.

The mean depth ratings in Fig. 6 do not show the specific distributions of negative, positive or zero ratings. We therefore visualized these in Fig. 7, through stacked bar plots in which the proportions of each response category are depicted. Each response is binned either in a category called receding (all negative responses), surface (all zero responses) or protruding (all positive responses). These types of plots are shown for each colour type and participant group separately. We will discuss these distributions descriptively, sketching the most interesting observations.

For conventional colours, laypeople showed the highest mean percentage surface percepts compared to art historians, and artists (see Table 6 for means and standard deviations for proportions of depth percepts). Artists reported the highest mean percentage protruding percepts followed by art historians, and laypeople. For receding percepts, artists scored slightly higher than art historians and laypeople.

In the case of fluorescent colours, a more consistent pattern emerges in that all participant groups report mostly protruding percepts (see Table 7 for means and standard deviations for proportions of depth percepts). Mean percentages of surface and receding percepts are quite low. 
Table 7.

Means and standard deviations for proportions of depth percepts for fluorescent colours in each participant group.

\begin{tabular}{|c|c|c|c|c|c|c|}
\hline \multirow[t]{3}{*}{ Participant group } & \multicolumn{6}{|c|}{ Depth percept } \\
\hline & \multicolumn{2}{|c|}{ Protruding } & \multicolumn{2}{|c|}{ Surface } & \multicolumn{2}{|c|}{ Receding } \\
\hline & $M$ & SD & $M$ & SD & $M$ & SD \\
\hline Artists & 0.86 & 0.13 & 0.06 & 0.04 & 0.10 & 0.10 \\
\hline Art historians & 0.88 & 0.05 & 0.05 & 0.05 & 0.08 & 0.02 \\
\hline Laypeople & 0.81 & 0.11 & 0.09 & 0.07 & 0.11 & 0.05 \\
\hline
\end{tabular}

$M$ and SD represent mean and standard deviation, respectively.

When zooming in on the colours that received the highest percentage of ratings in each depth category, we can see that for conventional colours, pink and red are seen as most protruding for artists (80\%), yellow for art historians $(67.5 \%)$, and red for laypeople (60\%). For surface percepts, pistachio, cream yellow, and grey are the three highest ranked colours, in various orders for each participant category (laypeople: pistachio $>$ cream yellow $>$ grey; art historians: cream yellow $>$ grey $>$ pistachio; artists: cream yellow $>$ pistachio $>$ grey). For all participant groups, pistachio had the highest proportion of receding ratings, closely followed by dark green.

\subsubsection{Does Fluorescence Affect Perceived Depth Differently for Warm and Cool Colours?}

A closer inspection of Fig. 6 reveals that not all fluorescent colours are perceived equally protruding, and this difference seems to be situated along the warm/cool colour dimension (i.e., blue and green vs. red, yellow, and pink). However, the conventional variants of the cool fluorescent colours were also rated less protruding. In this analysis, we asked whether the fluorescencerelated depth effect interacted with colours situated either on the cool side or the warm side of the warm/cool colour dimension. To do so, we created a new variable "colour warmth" where green and blue were grouped together as cool colours, and red, yellow, and pink as warm colours. In Table 8, the relevant descriptive statistics are summarized for each combination of colour warmth and fluorescence (visualised in Fig. 8). It is clear that the fluorescence-related depth effect holds across the different colour categories and participant groups. This is confirmed by the statistical analysis summarised in Table 9, where only main effects of colour and colour warmth are observed. This indicates that fluorescent colours are, on average, perceived as more protruding compared to conventional colours, and that cool colours are on average perceived as less 
Table 8.

Means and standard deviations for rating as a function of participant group, fluorescence and colour warmth.

\begin{tabular}{|c|c|c|c|c|c|c|c|c|}
\hline \multirow[t]{3}{*}{ Participant group } & \multicolumn{8}{|c|}{ Colour } \\
\hline & \multicolumn{2}{|c|}{$\begin{array}{c}\text { Cool } \\
\text { conventional } \\
\text { colours }\end{array}$} & \multicolumn{2}{|c|}{$\begin{array}{c}\text { Cool } \\
\text { fluorescent } \\
\text { colours }\end{array}$} & \multicolumn{2}{|c|}{$\begin{array}{c}\text { Warm } \\
\text { conventional } \\
\text { colours }\end{array}$} & \multicolumn{2}{|c|}{$\begin{array}{l}\text { Warm } \\
\text { fluorescent } \\
\text { colours }\end{array}$} \\
\hline & $M$ & SD & $M$ & SD & $M$ & SD & $M$ & SD \\
\hline Artists & 0.22 & 1.47 & 1.11 & 0.83 & 1.23 & 0.75 & 2.18 & 0.55 \\
\hline Art historians & 0.40 & 1.08 & 1.37 & 0.91 & 0.79 & 0.89 & 2.04 & 1.10 \\
\hline Laypeople & 0.30 & 0.73 & 1.08 & 0.72 & 0.64 & 0.80 & 1.70 & 1.00 \\
\hline
\end{tabular}

$M$ and SD represent mean and standard deviation, respectively.

\section{Table 9.}

Results of repeated measures ANOVA for depth ratings in function of participant group, fluorescence and colour warmth.

\begin{tabular}{lccrrc}
\hline Predictor & $\mathrm{df}_{\text {Num }}$ & $\mathrm{df}_{\text {Den }}$ & \multicolumn{1}{c}{$F$} & \multicolumn{1}{c}{$p$} & $\eta_{\mathrm{g}}^{2}$ \\
\hline Participant group & 2 & 57 & 1.03 & 0.363 & 0.02 \\
Colour & 1 & 57 & 79.30 & $<0.001$ & 0.23 \\
Warmth & 1 & 57 & 34.36 & $<0.001$ & 0.12 \\
Participant group $\times$ Colour & 2 & 57 & 0.33 & 0.720 & 0.00 \\
Participant group $\times$ Warmth & 2 & 57 & 2.38 & 0.102 & 0.02 \\
Colour $\times$ Warmth & 1 & 57 & 1.55 & 0.218 & 0.00 \\
Participant group $\times$ Colour $\times$ Warmth & 2 & 57 & 0.21 & 0.815 & 0.00 \\
\hline
\end{tabular}

$\mathrm{df}_{\mathrm{Num}}$ indicates degrees of freedom of the numerator; $\mathrm{df}_{\mathrm{Den}}$ indicates degrees of freedom of the denominator; $\eta_{\mathrm{g}}^{2}$ indicates generalized eta-squared.

protruding compared to warm colours. Neither of these main effects interacts with participant group, indicating that it is stable and similar across observer types.

\subsection{Comparing Results of All Specific Designs, Per Participant Type}

Besides knowing the mean depth ratings of all colours and of each colour separately, it is valuable to analyse the mean depth ratings of each colour depending on its use in a specific design. In other words, how does the same colour appear in a changed context, in which the colours are the same, but their position differs and in which the fluorescent colours are switched with their conventional counterpart. In each of the four series, special attention goes to 
the comparison of the original (containing fluorescent panels) with the original conventional variant (in which all fluorescent panels are swapped with conventional variants). This brings us to our next research question: do participants still experience colour depth when all fluorescent colours are replaced with their conventional variants? Other expected (and unexpected) ratings because of colour interactions, as listed in subsection 2.1, will be discussed. Again, all results will be divided per participant group to allow a comparative study. Because these analyses pertaining to specific designs and colours result in a lot of statistical tests, we only report the statistically significant ones throughout the text. For a complete overview of all outcomes of the statistical analyses, we refer to the Supplementary Material.

\subsubsection{Effingham I}

A large difference between the original (design 9), containing fluorescent colours in three out of four panels, and the conventional variant (design 13) is apparent (Fig. 9). When comparing them, it appears that all fluorescent colours received a much higher average depth rating, in line with the finding reported earlier on the aggregate data. Indeed, this observation holds for both fluorescent blue $\left[F(1,57)=8.29, p=0.006, \eta_{\mathrm{g}}^{2}=0.05\right]$ as well as fluorescent yellow $\left[F(1,57)=11.79, p=0.001, \eta^{2}{ }_{\mathrm{g}}=0.07\right]$. In the case of fluorescent blue, neither panel position nor participant group or any of their interactions influenced the mean depth ratings. In the case of fluorescent yellow, a main effect of participant group emerged $\left[F(2,57)=4.74, p=0.01, \eta_{\mathrm{g}}^{2}=0.10\right]$. Tukey-corrected pairwise comparisons indicated that this main effect was driven by the artists on average giving higher depth ratings for fluorescent yellow than the laypeople $[t(57)=3.06, p=0.01, d=0.79]$.

Now we turn to a comparison between designs 9 and 5. In design 9, two fluorescent blue colours were presented, compared to one fluorescent yellow band. In design 5, this was reversed and two fluorescent yellow bands were presented, and only one fluorescent blue. In short, none of the mean depth ratings statistically differed for any of the participant groups in designs 9 and 5. Similarly so, when the fluorescent blue colours were presented together with a conventional yellow colour rather than a fluorescent one, this also had no impact on the mean depth ratings. Finally, when analysing the ratings of conventional orange, none of the specific designs had any impact on the mean depth rating.

\subsubsection{Chocorua IV}

In Fig. 10, the mean depth ratings of Chocorua IV are summarized. Again, a strong and consistent effect of fluorescent colours is observed for both fluorescent red $\left[F(1,57)=49.23, p<0.0001, \eta_{\mathrm{g}}^{2}=0.25\right]$ and yellow $[F(1,57)=$ $\left.39.46, p<0.0001, \eta_{\mathrm{g}}^{2}=0.12\right]$. No effect of participant group was observed, not 
even for yellow colours. This indicates that the difference observed between artists and laypeople for yellow colours does not generalize to this design.

Now we turn to the more specific comparisons associated with specific designs. In designs 11 and 3 , fluorescent red is presented together with fluorescent yellow, whereas this is not the case in design 14. However, no effect of this context was observed when comparing the mean depth ratings for fluorescent red across these three designs and all participant groups. Interestingly, the presence of fluorescent red did have an influence on the mean depth ratings of the colour yellow, when comparing designs 14 and $7[F(1,57)=12.38, p=0.0009$, $\left.\eta_{\mathrm{g}}^{2}=0.06\right]$. That is, in the presence of a fluorescent colour, yellow was rated as more protruding. This effect did not depend on participant group.

The grey and dark green panels, which remained the same across designs, were overall rated as negative. Here it is interesting to consider whether the perception of grey varies depending on the presence of fluorescent colours in the display. When comparing designs 14 and 7, designs 14 and 11, or designs 14 and 3, no differences in the mean depth ratings of grey emerged. In the case of dark green, we compared designs 14 and 11, as well as 7 and 11, to assess whether the presence of fluorescent yellow interacted with the perception of dark green. In the comparison between designs 14 and 11, no such effects were observed. However, when comparing designs 7 and 11, a main effect of design emerged $\left[F(1,57)=10.47, p=0.002, \eta_{\mathrm{g}}^{2}=0.05\right]$. Although the interaction between design and participant group was not statistically significant, the artists seem to be mainly driving this main effect. That is, the presence of fluorescent colours in design 11 causes the dark green to be perceived as more receding compared to design 7 containing no fluorescent colours.

\subsubsection{Union $I$}

This series (Fig. 11) consists only of designs with three colours. Again, the fluorescent effect is quite pronounced when comparing designs 6 and $10[F(1$, $\left.57)=27.37, p<0.0001, \eta_{\mathrm{g}}^{2}=0.18\right]$, with no differences between participant groups. The position of fluorescent pink did not matter for its mean depth rating (comparison of designs 6 and 2). Pistachio was also evaluated similarly, independent of the size of the panel it was in (design 2 compared to designs 6 and 10).

\subsubsection{Sanbornville III}

In comparing designs 8 (the original) and 4 (the original, conventional variant), a significant change is visible when the fluorescent colours are swapped with conventional ones $\left[F(1,57)=30.13, p<0.0001, \eta_{\mathrm{g}}^{2}=0.18\right]$ (Fig. 12). Independent of the context it was presented in (designs $8,12,15)$, fluorescent green was rated similarly across participant groups. 
In designs 8 and 4, grey-blue was either presented together with fluorescent green or conventional green. Despite this different context, mean depth ratings for grey-blue were not influenced by this differential context. Similarly so for cream yellow in designs 12 and 15, no influence of differential context was observed for the mean depth ratings.

\subsection{Contrast Effects}

When processing the data, changes in ratings for the same colours in the same designs were noticed when comparing the results. We will refer to these effects as contrast effects. For example, Chocorua IV contains two grey bars in panels 1 and 3 in each design. It struck us that the artist group changed their rating much more than the other participant groups, for the same physical colour. In order to visualise this effect, we created the graphs below (Fig. 13), based on the three series that included at least four panels (Effingham I, Chocorua IV and Sanbornville III). Each mosaic shows the sign of the difference score obtained by subtracting the rating for panel 3 from the rating for panel 1 . We obtained these difference scores for each design and participant separately, and plotted them depending on whether no change (white), a positive change (blue) or a negative change (red) occurred.

In comparing these graphs across participant groups, it is apparent that the artists appeared to see much stronger contrast effects than the other two groups, especially in the Chocorua IV and Sanbornville III design groups. Half of the artists rated the grey colour (panels 1 and 3) of the Chocorua IV design 14 differently and 11 of the 20 artists saw the cream yellow colour appear differently in design 15 of the Sanbornville III series. In the Effingham I design group, there are some contrast effects, especially for the conventional blue colour variant, but they are less pronounced than in the other series. To assess this contrast effect statistically, we counted the number of switches for each participant (ignoring the sign) for each design group, and we estimated whether the proportion of switches was different between participant groups using a mixed-effects logistic regression model. This model revealed a significant difference between the artists and laypeople $[\beta(\mathrm{SE})=2.24(0.67), z=$ $3.35, p=0.0009]$, but none between the Art Historians and Laypeople group $(\beta(\mathrm{SE})=0.40(0.69), z=0.58, p=0.56)$. No effects of design group were observed (see Supplementary Materials for full model output).

\section{Conclusion and Discussion}

This case study on the experience of colour depth, through fifteen stimuli based on colour combinations of four Irregular Polygons paintings, shows that 
fluorescent colours (blue, red, pink, yellow and green) are experienced as protruding much more strongly than conventional colours. In this case, the fluorescent effect is additive, which means that the difference between fluorescent and conventional colours remains the same, regardless of warm-cold colour contrasts. Analysis revealed that when the fluorescent colour is exchanged for a conventional variant, the depth experience of that non-fluorescent colour is much less significant. Interestingly, the findings suggest that in some cases, the switch to a fluorescent colour influences the experience of the neighbouring colour in the same design, as illustrated by the yellow and dark green colour in the Chocorua VI series. In general, the differences between the participant groups are relatively small. When analysing the ratings of each colour separately though, we could see that artists did experience relatively more depth in both fluorescent and conventional colours, whereas laypeople generally gave less pronounced ratings, in particular for non-fluorescent colours (they rated them ' 0 ' much more often, cf. Fig. 7). As expected, the ratings given by the art historians were comparable to those of the artists, although their results were less pronounced for the conventional colours. The knowledge effect of the $40 \%$ of art historians who claimed to have strong knowledge of Stella's work, did not interact with the fluorescence effect. They even had lower ratings than the other art historians. Further, it was interesting to discover that the artists experienced more contrast effects, as they gave different ratings to different panels (of identical colour and shape) in the same design, depending on the position of the panel.

The outcome of this experiment empirically confirms that fluorescent colours appear as strongly protruding and because of this, in some cases, they might influence the conventional colours in the same design. This has strong implications when reimporting these findings in art historical practice. Frank Stella's attempt to make these paintings appear as 'flat and frontal', as mentioned in subsection 1.1, didn't succeed. As Judd already proclaimed in his criticism, Stella will not overcome the fact that illusion is an inseparable quality of painting. That is why, after his Irregular Polygons series, Stella slowly started to embrace illusion in his work as 'working space'. In light of the polemics in art criticism (cf. subsection 1.1), it is undeniable that the visual effects generated through these colour combinations are - contrary to what Michael Fried assessed - causing the illusion of depth. Up to now, with what we know from the experiment, our findings are most in line with Rose and Krauss' theory of 'abstract' illusionism. Their descriptions of the visual effects of the Irregular Polygons paintings, in which they saw telescoping coloured shapes which made these painting flip-flop between 2D (flatness) and 3D (illusion), are closely related to our results. Unfortunately, neither of them payed much attention to the impact of fluorescent colours in their theories. The method 
and outcome of this experiment will play an important role in future planned revisions of these art historical claims.

Several limitations of the present case-study should be acknowledged: First of all, the phenomenological part is a collection of overlapping first-person observations and serves as a starting point for further scientific research. We focused solely on depth experiences caused by colours and their interaction, and did not include the influence of shape and the impact of the visible canvas spaces between shapes. We have planned a future investigation, in collaboration with the Van Abbe museum in Eindhoven, in which we will work with the real Effingham I painting. This way we can make a comparison with this study, to find out to what extent the shapes and texture of the painting influence the experience of colour depth. Furthermore, this case study used all the most common fluorescent colours, with the exception of fluorescent orange. A similar design series based on an Irregular Polygons painting containing this colour, should be studied as well in the future. Our expectation for this colour is that it will lead to similar depth ratings to those of fluorescent red and pink. Furthermore, it might be beneficial to set up a similar experiment only with fluorescent colours. In this case, it might be the case that none of the colours will be rated as surface (0).

Finally, our findings support the claim that reproductions of fluorescent artworks cannot possibly recreate the same visual experience as the original. Researchers and critics should keep this in mind when discussing such artworks. This investigation into the influence of fluorescent colours on depth experience when looking at Stella's paintings, provides an example of how art historical studies can be supplemented with scientific methods.

\section{Acknowledgments}

First of all, we would like to thank the Academy of Fine Arts in Berchem (Antwerp) to make their office available for the experiment and for their help in recruiting participants. Our gratitude to artists Goedele Peeters and Jelle Nicolaï for their assistance in making the stimuli. Special thanks to Luca Bonetti corp. for providing us with the necessary material and technical information about Stella's paintings and to Doris Aach for sending us the valuable archival material that we used to describe the phenomenological part. Lastly, many thanks to the reviewers for helping us to improve the manuscript. This research was supported by a doctoral fellowship awarded to Stefanie De Winter and a postdoctoral fellowship awarded to Pieter Moors, both by the Fund for Scientific Research Flanders (FWO). Johan Wagemans is supported by a Methusalem grant (METH/14/02). This experiment was approved by the Social and Societal Ethics Committee (SMEC) at the KU Leuven. 


\section{Notes}

1. An overview of all the works is illustrated in the book: Frank Stella: Irregular Polygons 1965-66 (Kennedy, 2010).

2. Warhol made large series of these silkscreen paintings combining lots of different colours. In this case, from Angela Little's description, it seems that the 'magenta' and 'red' flowers are fluorescent and the yellow one is a conventional colour. The following link provides an image of the discussed silkscreen painting online (http://anoluck.com/wp/wp-content/ uploads/2014/05/CH-823858.jpg) (accessed May 2018).

3. Shortly after Frank Stella started to use Day-Glo paints, other New York artists like James Rosenquist (1933) also started to use a combination of fluorescent and conventional colours in their figurative work, for example: F-111 (1964-65).

4. This effect depends on the amount of ultraviolet in the surrounding light of the environment.

5. The illustrations used in books and online publications often describe these artworks as 'fluorescent alkyds and enamel paints' without pointing out which specific colours are fluorescent. Thanks to the cooperation of several art galleries and museums, we were able to find out which colours were fluorescent.

6. Figure 1 shows photographs of the artworks and the stimuli, all photographed under the same natural light conditions. Differences in colour due to automatic corrections of the camera might appear. As mentioned in the introduction, it is not possible to photograph or reproduce fluorescent colours. Beside the fact that we cannot see the fluorescent effect, the camera automatically darkens conventional colours, creating a distorted image. Some fluorescent colours (e.g., the fluorescent green in Sanbornville III looks much darker than the one in the designs) appear darker because of aging conditions. Also, the interaction with the carrier (cotton duck) might influence the appearance of the fluorescent colours because of the transparent character of these paints.

7. Colourmatch numbers of each used fluorescent silkscreen ink of the brand Publivenor: red: FL 201; yellow: FL 101; Blue: FL 301; green: FL 401; pink: FL 241. All conventional colours were mixed using the following colourmatch numbers: yellow: 106; red: 210; blue: 300. To add white, we used printperfect Lac FF New. We measured all conventional colours with an Avantes spectrometer (the RGB value of each conventional colour used in the designs is mentioned in Fig. 1). 
8. To conduct the Ishihara test we used an app on an Android tablet. The name of the app is Color Blindness Test.

\section{References}

Aach, H. (1970). On the use and phenomena of fluorescent pigments in painting, Leonardo 3 , 135-138.

De Winter, S. (2014 ). Interview with Frank Stella, unpublished interview, transcribed. Peter Freeman Gallery, New York, NY, USA (January 20 ${ }^{\text {th }}, 2014$ ).

Edwards, A. S. (1955). Effect of color on visual depth perception. J. Gen. Psychol. 52, 331333.

Fried, M. (1965). Three American Painters, exhibition catalog. Fogg Art Museum, Harvard University, Cambridge, MA, USA.

Fried, M. (1966). Shape as form: Frank Stella's new paintings. Artforum 5, 18-27.

Gregory, R. L. (1980). Perceptions as hypotheses. Philos. Trans. R. Soc. Lond. B Biol. Sci. 290, 181-197.

Gregory, R. L. (1990). Eye and Brain: The Psychology of Seeing, 4th ed. Princeton University Press, Princeton, NJ, USA.

Itten, J. (1970). The Elements of Color. John Wiley \& Sons, New York, NY, USA.

Johnston-Feller, R. (2001). Color Science in the Examination of Museum Objects: Nondestructive Procedures. Getty Conservation Institute, Los Angeles, CA, USA.

Judd, D. (1965). Specific Objects, Arts Yearbook, 8, 74-82.

Kennedy, B. P. (2010). Frank Stella: Irregular Polygons, 1965-66, exhibition catalogue. Hood Museum of Art, Dartmouth College, Hanover, NH, USA.

Krauss, R. (1968). On Frontality. Artforum 5, 40-46.

Krauss, R. (1971). Stella's new work and the problem of series, Artforum 10, 40-44.

Lejeune, A. (2015). Perspective et Géométral - Problématisation de la Sculpture aux ÉtatsUnis (1966-1973), Les Presses du Réel, Dijon, France.

Litt, S. (2011). Frank Stella's luminous "Irregular Polygon" series is reunited at the Toledo Museum of Art.https://www.cleveland.com/arts/index.ssf/2011/04/frank_stellas_luminous_ irregul.html. [accessed May 2018].

Little, A. (1965). Shades of meaning, Color Eng. 3, 4.

Little, A. (1966). Shades of meaning, Color Eng. 4, 3, 5.

Livingstone, M. (2002). Vision and Art: The Biology of Seeing. Harry N. Abrams, New York, NY, USA.

McGlinchey, C. and Pratt, E. (2000). Exploring boundaries in painting technique. MoMA 3, 6-9.

Rose, B. (1967). American Art since 1900; A Critical History. Praeger Publishers, New York, NY, USA.

Rose, B. (1967). Abstract illusionism. Artforum (October 1967), 33-37.

Rubin, W. S. (1970). Frank Stella, The Museum of Modern Art, New York, NY, USA.

Stella, F. (1986). Working Space, Vol. 40. Harvard University Press, Cambridge, MA, USA.

Streitel, S. G. (2009). Fluorescent pigments (daylight). Kirk-Othmer Encyclopedia of Chemical Technology, John Wiley \& Sons, New York, NY, USA. 
Toledo Museum of Art (2011). Masters Series: An Evening with Frank Stella, https://www .youtube.com/watch?v=W9qL6XVtPZM [accessed May 2018].

Van Gelder, H. (2003). The instantaneous grace of a split-second glance: A modernist myth of timelessness revisited, in: The Enduring Instant: Time and the Spectator in the Visual Arts, A. Roesler-Friedenthal and J. Nathan (Eds), pp. 127-133. Mann Verlag, Berlin, Germany.

Van Gelder, H. (2004). The fall from grace. late minimalism's conception of the intrinsic time of the artwork-as-matter, Interval(les) 1, 83-97.

Vos, J. J. (2008). Depth in colour, a history of a chapter in physiologie optique amusante. Clin. Exp. Optom. 91, 139-147. 


\section{Appendix}

Example of a questionnaire used in the experiment. Translation of legend: $-3=$ very strongly receding; $-2=$ strongly receding; $-1=$ slightly receding; $0=$ neither receding nor protruding; $1=$ slightly protruding; $2=$ strongly protruding; 3 = very strongly protruding.
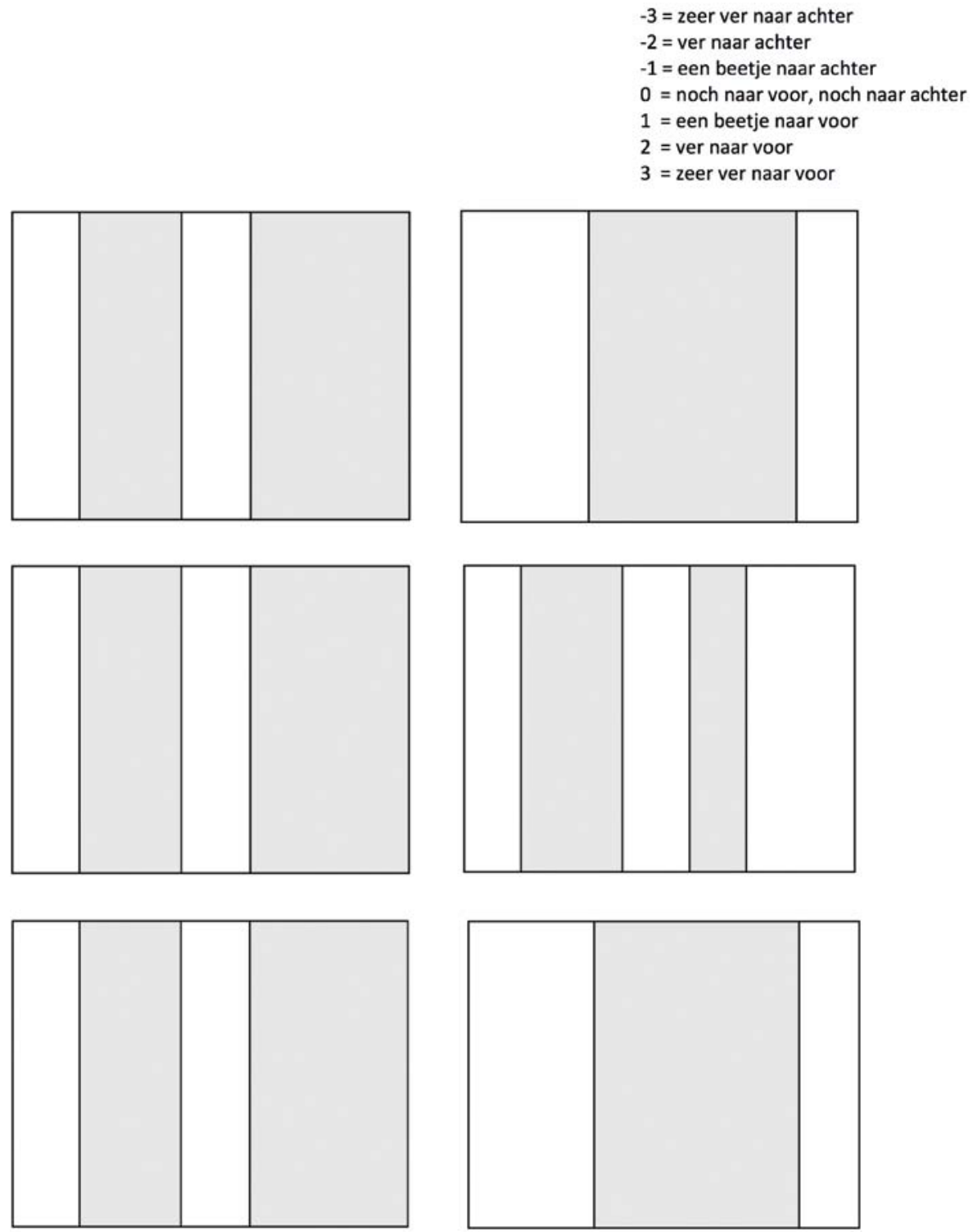